\title{
Swath-altimetry measurements of the main stem Amazon River: measurement errors and hydraulic implications
}

\author{
M. D. Wilson ${ }^{1}$, M. Durand ${ }^{2}$, H. C. Jung ${ }^{3,4}$, and D. Alsdorf ${ }^{2}$ \\ ${ }^{1}$ Department of Geography, University of the West Indies, St. Augustine, Trinidad \& Tobago \\ ${ }^{2}$ Byrd Polar Research Center and School of Earth Sciences, Ohio State University, 125 South Oval Mall, Columbus, \\ OH 43210, USA \\ ${ }^{3}$ Office of Applied Sciences, NASA Goddard Space Flight Center, 8800 Greenbelt Road, Greenbelt, MD 20771, USA \\ ${ }^{4}$ Science Systems and Applications Inc., 10210 Greenbelt Road, Lanham, MD 20706, USA \\ Correspondence to: M. D. Wilson (matthew.wilson@sta.uwi.edu)
}

Received: 22 June 2014 - Published in Hydrol. Earth Syst. Sci. Discuss.: 6 August 2014

Revised: 20 March 2015 - Accepted: 24 March 2015 - Published: 22 April 2015

\begin{abstract}
The Surface Water and Ocean Topography (SWOT) mission, scheduled for launch in 2020, will provide a step-change improvement in the measurement of terrestrial surface-water storage and dynamics. In particular, it will provide the first, routine two-dimensional measurements of water-surface elevations. In this paper, we aimed to (i) characterise and illustrate in two dimensions the errors which may be found in SWOT swath measurements of terrestrial surface water, (ii) simulate the spatio-temporal sampling scheme of SWOT for the Amazon, and (iii) assess the impact of each of these on estimates of water-surface slope and river discharge which may be obtained from SWOT imagery. We based our analysis on a virtual mission for a $\sim 260 \mathrm{~km}$ reach of the central Amazon (Solimões) River, using a hydraulic model to provide water-surface elevations according to SWOT spatio-temporal sampling to which errors were added based on a two-dimensional height error spectrum derived from the SWOT design requirements. We thereby obtained water-surface elevation measurements for the Amazon main stem as may be observed by SWOT. Using these measurements, we derived estimates of river slope and discharge and compared them to those obtained directly from the hydraulic model. We found that cross-channel and along-reach averaging of SWOT measurements using reach lengths greater than $4 \mathrm{~km}$ for the Solimões and $7.5 \mathrm{~km}$ for Purus reduced the effect of systematic height errors, enabling discharge to be reproduced accurately from the water height, assuming known bathymetry and friction. Using cross-sectional averaging and $20 \mathrm{~km}$ reach lengths, results
\end{abstract}

show Nash-Sutcliffe model efficiency values of 0.99 for the Solimões and 0.88 for the Purus, with 2.6 and $19.1 \%$ average overall error in discharge, respectively. We extend the results to other rivers worldwide and infer that SWOT-derived discharge estimates may be more accurate for rivers with larger channel widths (permitting a greater level of cross-sectional averaging and the use of shorter reach lengths) and higher water-surface slopes (reducing the proportional impact of slope errors on discharge calculation).

\section{Introduction}

The hydrological cycle is of fundamental importance to life and society and river gauges have long formed a basis our hydrological understanding, often providing real-time measurement capabilities of river stage or discharge and information for water management and flood warning. Yet existing in situ gauge networks are unevenly distributed globally, with a distinct lack of measurements obtained in developing countries, particularly for areas with low population (Vorosmarty et al., 2001; Shiklomanov et al., 2002). In addition, gauging stations are highly variable in their accuracy and are under threat. The United States has around 7000 stream gauges but, nevertheless, more than $20 \%$ of basins are not gauged adequately (USGS, 1998), contributing to an insufficient knowledge of available national water resources (NSTC, 2004).

Over the latter half of the 20th century, increasing numbers of gauging stations in the United States with 30 or more years 
of recording were discontinued each year; in the mid-1990s, this represented about $4 \%$ of the long-record stations being discontinued (USGS, 1998). The situation globally is substantially worse than in the United States, with much of the globally significant discharge occurring in sparsely gauged catchments (Alsdorf et al., 2003). The gauge density in the Amazon, expressed as number of gauges per unit of discharge, is around 4 orders of magnitude less than what is typical in the eastern United States (Alsdorf et al., 2007b). Worldwide, Fekete and Vörösmarty (2007) indicated that the number of data available through the Global Runoff Data Centre (GRDC) is in sharp decline, and now stands at less than 600 discharge monitoring stations, down from a peak of around 5000 in 1980.

Remote sensing has been shown to be a valuable addition to ground-based gauges, with the added benefit of being able to reduce data access issues in international river basins, which contribute to greater than $50 \%$ of global surface flows (Wolf et al., 1999) and where obtaining information about upstream flows can be politically challenging (e.g. Hossain et al., 2007). Satellite altimetry, in particular, has been used extensively to obtain water elevations of inland river and lake systems, including data from the European remote sensing (ERS) satellite, TOPEX/Poseidon, Envisat and Jason 1 and 2 (e.g. Berry et al., 2005; Birkett, 1998). For example, Birkett et al. (2002) used TOPEX/Poseidon altimetry data to analyse surface-water dynamics along the Amazon River and characterised the spatially and temporally variable surface-water gradient as between $1.5 \mathrm{~cm} \mathrm{~km}^{-1}$ downstream and $4.0 \mathrm{~cm} \mathrm{~km}^{-1}$ upstream. Satellite altimetry has also been used to estimate river discharge. Birkinshaw et al. (2012) estimated discharge for the Mekong and Ob rivers using ENVISAT altimetry over $50 \mathrm{~km}$ river reaches, based on the Manning's resistance formulation of Bjerklie et al. (2003), and were able to obtain Nash-Sutcliffe efficiency values of $0.86-$ 0.90. Papa et al. (2012) used Jason-2 altimetry data to estimate flux from the Ganga and Brahmaptura rivers, based on in situ rating curves relating water elevation to discharge, and obtained errors of 13 and $6.5 \%$, respectively.

A limitation of profiling satellite altimetry for the analysis of river hydrology is that the nadir viewing geometry and narrow field of view leads to an incomplete coverage and a long revisit time. Currently operational satellite altimeters include the Ocean Surface Topography Mission (OSTM) on the Jason-2 platform (Lambin et al., 2010) which, as with its predecessors Jason-1 and TOPEX/Poseidon, has an orbital repeat time of around 10 days and a ground track spacing of $315 \mathrm{~km}$ at the Equator (Seyler et al., 2013). For rivers in the Amazon basin, the OSTM altimeter has been found by Seyler et al. (2013) to have a mean root mean square error (RMSE) of $\pm 0.31 \mathrm{~m}$ for rivers over $400 \mathrm{~m}$ wide. Using two parallel tracks to calculate water-surface slope, as is needed for the estimation of instantaneous discharge in the absence of in situ rating curves, this RMSE would lead to a maximum water-surface slope error of around $2 \mathrm{~mm} \mathrm{~km}^{-1}$ (cal- culated using $2 \times 0.31 \mathrm{~m} / 315 \mathrm{~km})$. However, this represents an average slope over a large river distance and does not reflect the likely spatial variability or curvature in the water surface due to a coarse spatial resolution. Although ascending and descending tracks may be combined to better represent this variability, errors in the estimate of water-surface slope and, hence, discharge would increase. In addition, to calculate water-surface slope, temporal interpolation of data in different tracks is needed, increasing errors particularly for smaller rivers with higher temporal variability or during periods of highly variable flow, such as flood events.

These limitations mean that, for the majority of rivers, satellite altimetry does not provide sufficient detail to capture the full spatial or temporal complexity of river hydrology. Profiling altimetry was shown by Alsdorf et al. (2007b) to entirely miss $32 \%$ of rivers in a global database, compared to only $1 \%$ of rivers being missed by an imager (based on the Terra 16-day repeat cycle, $120 \mathrm{~km}$ swath, $\sim 98^{\circ}$ inclination and sun-synchronous orbit).

Similar to river gauges, measurements obtained by profiling altimetry are usually spatially one-dimensional (i.e. they are either at one point or represent a full channel cross section), meaning that no information on water-surface area or two-dimensional patterns in water-surface slope is provided. However, synthetic aperture radar (SAR) interferometry work by Alsdorf et al. (2007a) has shown that water flow is both spatially and temporally complex, requiring twodimensional, multi-temporal measurements to be captured sufficiently. This means that our current, operational remote sensing has limited capability with regard to an important component of the water surface (Alsdorf et al., 2007b). Remote sensing has been used with some success to characterise hydraulic variables including surface-water area and elevation, water slope and temporal changes. However, none of the existing technologies are able to provide each commensurately, as needed to model accurately the water cycle (Alsdorf et al., 2007b).

The forthcoming Surface Water and Ocean Topography (SWOT) mission (Durand et al., 2010) aims to overcome existing limitations in remote sensing by using a swathaltimetry approach to measure surface-water elevation in two dimensions, providing both surface-water area and elevation simultaneously. Such measurements may allow watersurface slopes to be derived instantaneously and, therefore , potentially could provide estimates of river and floodplain discharge. The main objective of the work presented in this paper was to investigate the hydraulic implications of potential measurement errors in SWOT imagery (independently to other potential errors) for a reach of the main stem Amazon River and one of its tributaries. 


\section{The surface water and ocean topography mission}

Recommended for launch by the National Research Council Decadal Survey (NRC, 2007), SWOT will provide a substantial improvement in the availability of data on terrestrial surface-water storage and dynamics, achieving near-global water elevation measurements in large rivers and their large floodplains. The SWOT sensor is a Ka-band radar interferometer which will allow mapping of surface-water extent and elevation at a spatial resolution of around $70-250 \mathrm{~m}$, at centimetric vertical precision when averaged over targets of interest, every 2-11 days depending on the latitude (Durand et al., 2010; Rodríguez, 2014). Thus, SWOT will provide the first, routine two-dimensional measurements of water-surface elevation, allowing for the analysis of floodplain hydrodynamics and the estimation of river discharge. While SWOT will not replace a ground-based river gauge network, it will allow large ungauged rivers to be sampled and increase the level of detail and availability in river flow estimates. In addition, the two-dimensional measurements of surface water provided by SWOT will allow the detailed observation of floodplain and wetland hydrodynamics (Durand et al., 2010).

The approach used by SWOT is similar to that of LeFavour and Alsdorf (2005) and Kiel et al. (2006), who used Shuttle Radar Topography Mission (SRTM) elevation data of the water surface to obtain slopes of the Amazon and Ohio rivers and, subsequently, to estimate channel discharge. However, for the Amazon, LeFavour and Alsdorf (2005) found vertical errors of $5.51 \mathrm{~m}$ in water-surface elevations from Cband SRTM data, meaning that a long-reach length of $733 \mathrm{~km}$ was required to reduce errors in derived water-surface slopes to $1.5 \mathrm{~cm} \mathrm{~km}^{-1}$ for the accurate estimation of channel discharge (6.2\% error at Manacapuru; $7.6 \%$ at Itapeua). For SWOT, the science requirements are for a vertical precision of $10 \mathrm{~cm}$ in measurements of water-surface elevation and derived water-surface slopes with errors of no more than $1 \mathrm{~cm} \mathrm{~km}^{-1}$ when averaged over a $10 \mathrm{~km}$ reach length (Rodríguez, 2014). For comparison, using the simple method of LeFavour and Alsdorf (2005) to determine an appropriate reach length $\left(2 \sigma / S_{\min }\right.$, where $\sigma$ denotes the vertical precision of the measurements and $S_{\min }$ denotes the minimum slope required), indicates that, using a SWOT vertical precision of $10 \mathrm{~cm}$, to achieve water-surface slope errors of no more than $1 \mathrm{~cm} \mathrm{~km}^{-1}$, reach lengths of $20 \mathrm{~km}$ may be required and for $1.5 \mathrm{~cm} \mathrm{~km}^{-1}$, reach lengths of $13.3 \mathrm{~km}$. However, this simple method may be overly conservative and does not take into account the potential for averaging over channel cross sections. In this paper, we explore the implications of the SWOT science requirements on the derivation of water-surface slope and subsequent estimation of channel discharge.

\subsection{Virtual mission}

We used a virtual mission study of two-dimensional observations of water-surface elevation as may be obtained by
SWOT, for the estimation of discharge on a $\sim 260 \mathrm{~km}$ reach of the central Amazon River (Solimões) and one of its tributaries (Purus) in Brazil (Fig. 1a). The Amazon is a globally significant river, carrying around $20 \%$ of total global continental runoff (Richey et al., 1989) with a monomodal flood pulse passing annually down the river. The middle reaches of the Amazon are characterised by very low water-surface slopes of between 1 and $3 \mathrm{~cm} \mathrm{~km}^{-1}$ and significant backwater effects (Meade et al., 1991). In the study site, peak channel discharge of the Amazon is around $120000 \mathrm{~m}^{3} \mathrm{~s}^{-1}$, and the channel width varies between approximately 2 and $5 \mathrm{~km}$. Close to its confluence with the Amazon, the Purus is characterised by extremely low water-surface slopes (less than $1 \mathrm{~cm} \mathrm{~km}^{-1}$ ) and substantial backwater effects from the main channel. Peak channel discharge is around $18000 \mathrm{~m}^{3} \mathrm{~s}^{-1}$, with channel width varying between 0.6 and $1.7 \mathrm{~km}$.

The combination of low water-surface slope combined with high discharge in these rivers makes the estimation of discharge from SWOT challenging since water-surface slope errors may have a proportionately large impact. Here, we assessed the likely accuracy which may be possible, assuming knowledge of other factors such as channel geometry. Specifically, we aimed to (i) characterise and illustrate in two dimensions the errors which may be found in SWOT swathaltimetry measurements of terrestrial surface water; (ii) simulate the spatio-temporal sampling scheme of SWOT for the Amazon; and (iii) assess the impact of each on estimates of water-surface slope and river discharge which may be obtained from SWOT imagery. Note that, presently, the performance of the SWOT instrument in the case of flooded vegetation is unknown; thus, throughout this paper the words floodplain and wetland make reference to conditions with a clear view of the sky and without flooded vegetation.

We utilised the hydrodynamic model of Wilson et al. (2007) and Trigg et al. (2009) for the same reach of the Amazon. We used this model to generate water-surface elevation truth images for a 22-month period comprising more than a full flood cycle (Fig. 1b-c). These truth images were then temporally sampled to match the orbital characteristics of SWOT, and 2-D errors as defined by the SWOT design requirements were added. Thus, we obtained estimates of surface-water heights as may be observed by SWOT. From both the truth images and the simulated SWOT observations, estimates of river slope and discharge were then derived. A schematic summary of the virtual mission and methods used is shown in Fig. 2, with details provided in the following section. 


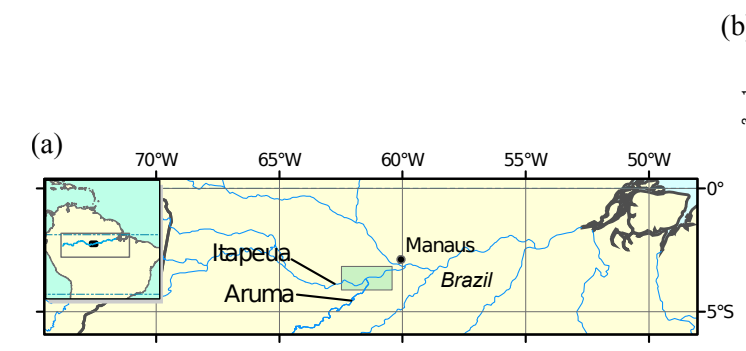

(b)

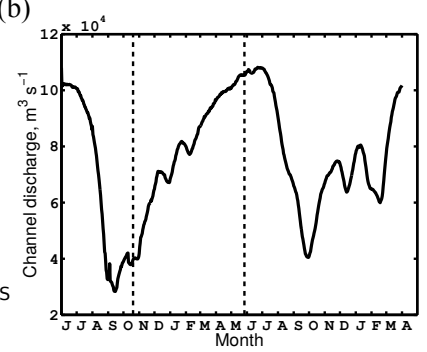

(c)

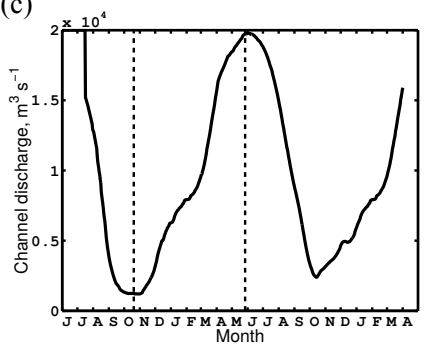

(d)

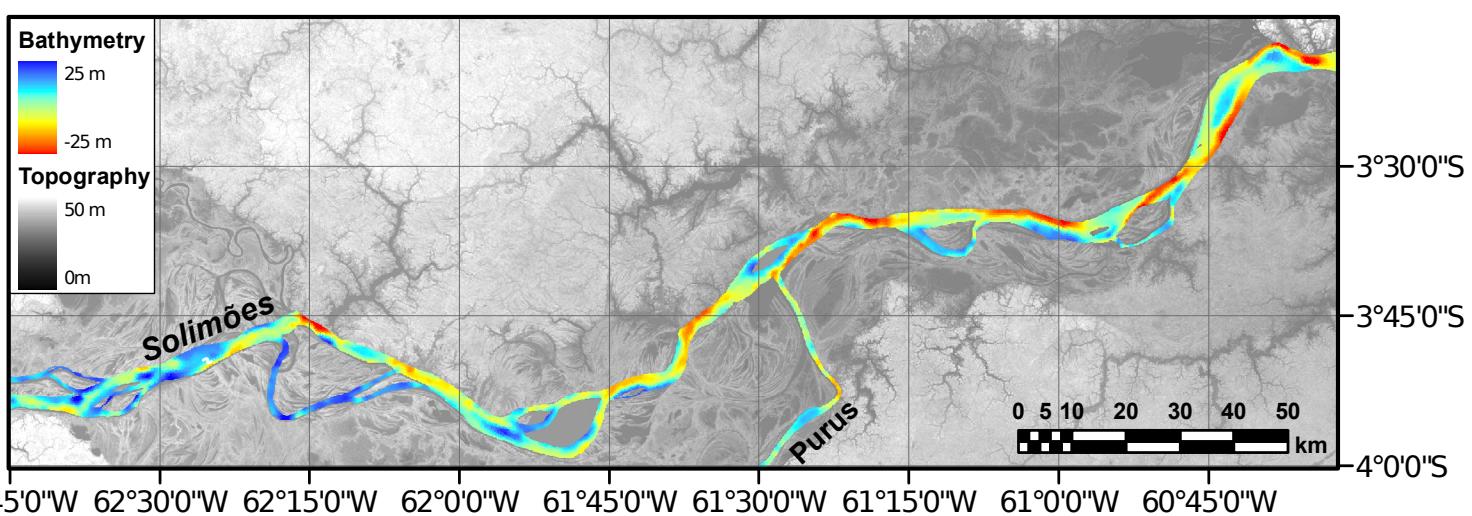

Figure 1. Study area: (a) location of site in the central Amazon, Brazil; (b) Solimões and (c) Purus inflow hydrographs; and (d) SRTM elevation fused with river bathymetry used in the hydraulic model.

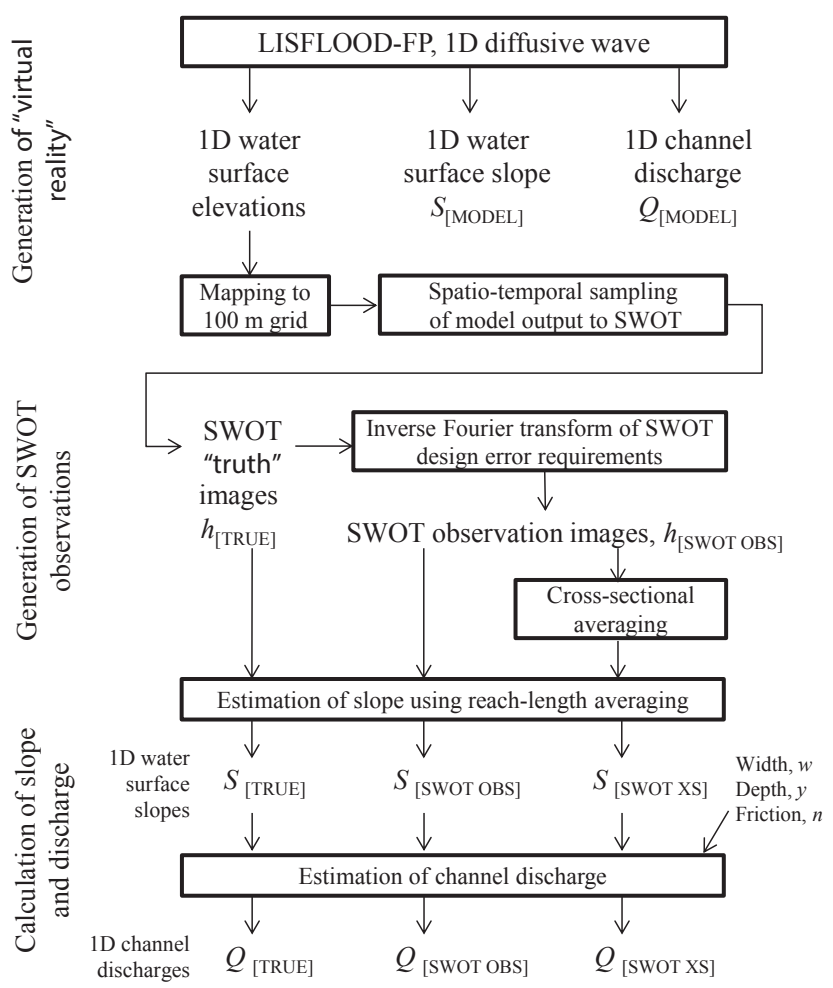

Figure 2. Schematic diagram of the methods used in this paper.

\section{Methods}

\subsection{Generation of water-surface truth images from hydrodynamic modelling}

In order to generate water elevation truth images, the hydrodynamic model code LISFLOOD-FP (Bates and De Roo, 2000) was used. LISFLOOD-FP consists of a 1-D representation of the river channel which is comprised of a series of channel cross sections and a 2-D floodplain representation. The formulation of LISFLOOD-FP used here was the one-dimensional diffusive wave formulation of Trigg et al. (2009) for channel flow (floodplain flow was excluded), allowing complex channel bathymetry and back propagation of flow. A detailed series of rectangular channel cross sections were used (124 for the Solimões and 48 for the Purus), with an average along-channel spacing of $2.4 \mathrm{~km}$ and each representing the average bed elevation for that location. Channel flow was implemented in the form:

$\frac{\partial Q}{\partial x}+\frac{\partial A}{\partial t}=q$,

$S_{0}-\frac{n^{2} P^{4 / 3} Q^{2}}{A^{10 / 3}}-\left[\frac{\partial y}{\partial x}\right]=0$,

where $Q$ is the volumetric flow rate in the channel, $A$ the cross-sectional area of the flow, $P$ is the wetted perimeter (approximated by channel width), $n$ is the Manning friction coefficient, $S_{0}$ is the channel bed slope, $q$ is the lateral flow into and out of the channel, $y$ is the channel depth, $x$ is the 
distance along the river and $t$ is time (Trigg et al., 2009). Note that $S_{0}$ is written so that it is greater than zero in the usual case where the bed elevation decreases in the downstream direction. The diffusion term, $[\partial y / \partial x]$, allows channel flow to respond to both the channel bed slope and the water-surface slope. This diffusive wave approximation of the full 1-D Saint Venant equations is solved using an implicit Newton-Raphson scheme.

In order to create truth images of water-surface elevation $\left(h_{\text {[RRUE] }}\right)$, 1-D channel water elevations were first mapped onto channel cross sections perpendicular to the channel centerline. Across each cross section, the elevation value of the channel centre was maintained; however, where two or more cross sections coincided (within $100 \mathrm{~m}$ ), the arithmetic mean of each was used. The resulting set of cross sections were then interpolated onto a 2-D regular grid using a nearestneighbour method at a spatial resolution of $100 \mathrm{~m}$. This was selected to approximately match the design requirements of SWOT as specified by Rodríguez (2014), although resolution will vary across the swath. While this method excluded potential minor cross-channel variation in water-surface elevation, variation along channel was incorporated fully, including any backwater effects.

Upstream boundary conditions (channel discharge) for the Solimões (Fig. 1b) and Purus (Fig. 1c) were derived from rating curves and river stage measurements at in situ gauges at Itapeua and Aruma (Fig. 1a), respectively, using data provided by the Agência Nacional de Águas (ANA), Brazil, for the period 1 June 1995 to 31 March 1997. River stage measured at Manacapuru was used as the downstream boundary condition. The model developed allowed the inclusion of a detailed river bathymetry (Fig. 1d), obtained in a field survey by Wilson et al. (2007) and described in detail by Trigg et al. (2009). In the study reach, the Solimões varies in width from around 1.6-5.6 km, with minimum bed elevation between -26.5 and $8.0 \mathrm{~m}$ (vertical datum: EGM96); the width of the Purus varies from 0.6 to $1.7 \mathrm{~km}$, with minimum bed elevation between -9.8 and $9.5 \mathrm{~m}$. Friction parameters for the model were obtained through a calibration based on the minimisation of RMSE calculated from river levels from four gauging stations internal to the model domain and model water-surface elevation obtained at a temporal resolution of $12 \mathrm{~h}$ (Trigg et al., 2009).

\subsection{Obtaining SWOT observations}

Water-surface elevations obtained from LISFLOOD-FP were used as truth onto which SWOT sampling and errors could be added, thereby allowing us to assess their hydraulic implications. Water surfaces were obtained from the model according to the SWOT spatio-temporal sampling scheme from an orbit with $78^{\circ}$ inclination, 22-day repeat, $97 \mathrm{~km}$ altitude, and $140 \mathrm{~km}$ swath width. The reach length was sufficient to be covered by six swaths in total in each 22-day cycle (three ascending, three descending), with each ground location be- (a)

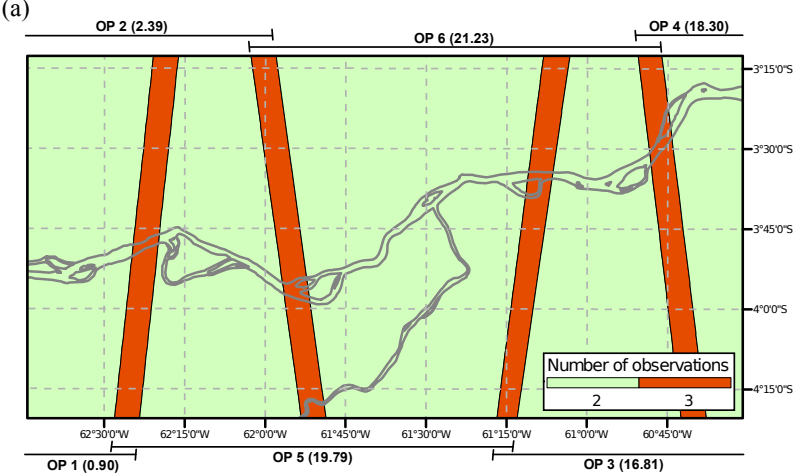

(b)

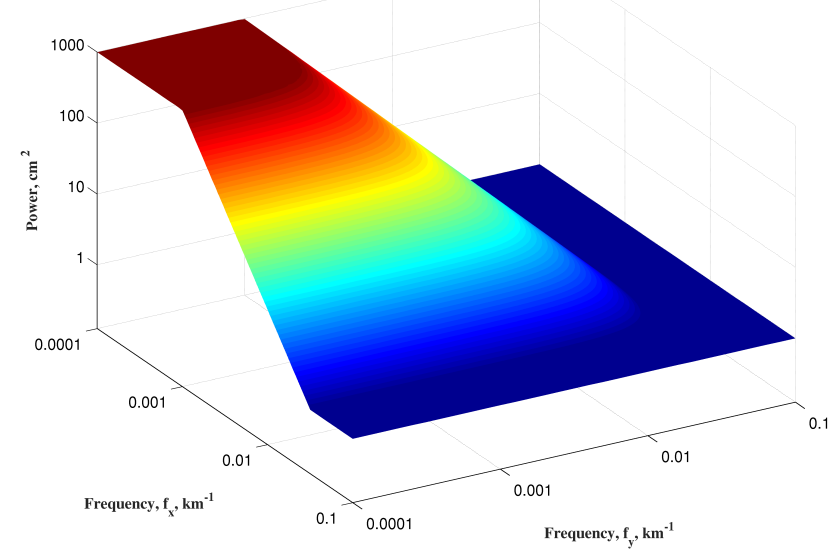

Figure 3. (a) Spatio-temporal sampling for a given cycle, including overpass timings (days from cycle start) during each 22-day cycle; (b) 2-D SWOT science requirements height error spectrum.

ing observed two or three times (Fig. 3a). Since the site is close to the Equator, this represents the minimum frequency in sampling which may be obtained by SWOT.

Onto the water-surface images, errors were added based on a two-dimensional height error spectrum derived from the SWOT design requirements (Fig. 3b). Two-dimensional spatially correlated SWOT errors were generated by inverse Fourier transform of the design requirements error spectrum (Rodríguez, 2014). Separate error fields each at $500 \mathrm{~m} \mathrm{spa-}$ tial resolution (resolution limited by computational power) were generated for each overpass in order to include longwavelength errors. Error fields were then resampled to model resolution $(100 \mathrm{~m})$, adding random noise in order to ensure that the total error variance (spectral, integral of the design requirements error spectrum) was correct.

We thereby obtained water-surface elevation measurements for the Amazon main stem as may be observed by SWOT, incorporating both spatially correlated and spatially random errors. Using these measurements, we derived estimates of river slope and discharge and compared them to those obtained directly from the hydraulic model. For completeness, we also compared discharge computed directly from the model output, i.e. the water-surface slope prior to 
adding slope errors. This allowed us to characterise the error in water-surface slope and discharge estimates from both the SWOT spatio-temporal sampling scheme and from the instrument measurement error.

\subsection{Calculation of slope and discharge from water-surface elevations}

Initially, single-pixel SWOT water-surface elevation measurements $\left(h_{[\text {SWOTOBS }]}\right)$ were extracted along the channel centerline and used to calculate water-surface slope $\left(S_{[\text {SWOTOBS }]}\right)$. Note that the water-surface slope is mathematically equal to the sum of the bed slope $\left(S_{0}\right)$ and downstream changes in water depth $[\partial y / \partial x]$ :

$S=S_{0}-\frac{\partial y}{\partial x}$.

$S$ was derived by along-reach averaging through the fitting of 1-D polynomials using least-square estimation to moving windows placed on the surface-water heights:

$S=-\frac{\sum x h-k \bar{x} \bar{h}}{\sum x^{2}-k \bar{x}^{2}}$,

where $k$ is the number of data points included in the moving window and $x$ is the distance of the water elevation observation, $h$, along the channel; the negative sign constrains the slopes to be greater than zero in the usual case when $h$ is decreasing in the downstream direction. The size of the moving windows used ranged from 0.5 up to $20 \mathrm{~km}$, with larger windows leading to greater along-channel smoothing of the data. This process was then repeated using crosssectional averages of SWOT water elevation measurements ( $h_{\text {[SWOTXS }]}$ ), extracted by taking the arithmetic mean of pixels across channel in a direction perpendicular to the channel centerline. Note that, while this may effectively reduce the random errors present, due to the inclusion of spatially correlated errors in the SWOT water elevations, this process may not necessarily lead to an improved estimate of discharge. $S_{\text {[SWOTXS] }}$ was calculated from $h_{\text {[SWOTXS] }}$ in the same way as $S_{\text {[SWOTOBS] }}$. For comparison and to assess accuracy of derived estimates of $Q$, true slope ( $S_{\text {[TRUE] }}$ ) was also calculated using water-surface elevation truth images $\left(h_{\text {[TRUE] }}\right)$ using Eq. (4).

For each water-surface slope $\left(S_{\text {[SwOTOBS] }}, S_{\text {[SwOTXS] }}\right.$, $\left.S_{\text {[TRUE] }}\right)$ at each reach length, discharge along the length of the channel was derived, following the method of LeFavour and Alsdorf (2005):

$Q=\frac{1}{n} w y^{5 / 3} S^{1 / 2}$,

where $w$ is the reach-averaged channel width, $y$ is the reachaveraged river depth and $S$ is the overall water-surface slope. In this paper, we assume that channel friction, width, and bed elevation are known. Thus, the focus here is on the impact of errors in observations of water-surface elevation and the derived estimates of water-surface slope on the estimation of discharge. Errors in $Q$ were approximated using first-order error propagation, via a Taylor series expansion:

$\sigma_{Q} \approx \frac{\partial Q}{\partial S} \sigma_{S}=\frac{1}{2} Q \frac{\sigma_{S}}{S}$.

Note that here we have isolated the uncertainty in $Q$ that derives from $S$. Hydrographs of discharge over time for given points on the channel were then extracted, with the temporal frequency of these determined by the SWOT sampling scheme. Thus, for most locations on the channel, two values of $Q$ were available in each 22-day cycle.

\subsection{Accuracy assessment of SWOT-derived discharge}

In addition to the discharge error approximation $\left(\sigma_{Q}\right)$ calculated in Eq. (6), hydrographs of channel discharge obtained using along-reach averaging $\left(Q_{[\text {SwOтовS }]}\right)$ and with added cross-sectional averaging ( $\left.Q_{\text {[SWOTXS] }}\right)$ were directly compared to hydrographs obtained using the true water-surface elevation $\left(Q_{\text {[TRUE] }}\right)$. RMSE was calculated for each hydrograph using

$\mathrm{RMSE}=\sqrt{\frac{\sum_{t=1}^{T}\left(Q_{[\mathrm{TRUE}]}^{t}-Q_{[\mathrm{PRED}]}^{t}\right)^{2}}{T}}$,

where $Q_{[\mathrm{TRUE}}^{t}$ is the observed channel discharge derived from true water-surface elevations at time $t, Q_{[\mathrm{PRED}]}^{t}$ is channel discharge derived from SWOT observations (either $Q_{\text {[SWOTовS] }}$ or $Q_{\text {[SWOTXS] }}$, and $T$ is the number of data in the time series. RMSE was then expressed as a percentage of mean $Q_{\text {[TRUE] }}$ :

$\mathrm{CV}_{\text {[RMSE }]}=\operatorname{RMSE} \cdot\left(\overline{Q_{[\text {TRUE }]}}\right)^{-1}$.

Finally, the Nash-Sutcliffe model efficiency coefficient (Nash and Sutcliffe, 1970) was calculated using:

$E=1-\frac{\sum_{t=1}^{T}\left(Q_{[\mathrm{TRUE}]}^{t}-Q_{[\mathrm{PRED}]}^{t}\right)^{2}}{\sum_{t=1}^{T}\left(Q_{[\mathrm{TRUE}]}^{t}-\overline{Q_{[\mathrm{TRUE}]}^{t}}\right)^{2}}$,

where values of $E$ range between $-\infty$ and 1.0, with 1.0 indicating a perfect match between $Q_{[\mathrm{TRUE}]}$ and $Q_{[\mathrm{PRED}]}$, and values less than zero indicating that the mean of $Q_{\text {[TRUE] }}$ is a better predictor of true channel discharge than $Q_{\text {[PRED] }}$ (Legates and McCabe, 1999). Generally, values of $E$ between 0.0 and 1.0 are considered as acceptable levels of performance (Moriasi et al., 2007).

\section{Results and discussion}

\subsection{Model output and generation of SWOT images}

The LISFLOOD-FP model was run for the full 22-month period between 1 June 1995 and 31 March 1997, taking around 
Table 1. Summary of along-channel variability in modelled watersurface slope and channel discharge at low and high water.

\begin{tabular}{|c|c|c|c|c|c|c|}
\hline & Variable & $\begin{array}{l}\text { Water } \\
\text { level }\end{array}$ & Minimum & Maximum & Mean & $\begin{array}{l}\text { Standard } \\
\text { deviation }\end{array}$ \\
\hline \multirow{4}{*}{ 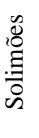 } & \multirow{4}{*}{$\begin{array}{l}\text { Slope } \\
\left(\mathrm{cm} \mathrm{km}^{-1}\right) \\
\text { Discharge } \\
\left(\mathrm{m}^{3} \mathrm{~s}^{-1}\right)\end{array}$} & Low & 0.15 & 9.57 & 1.37 & 1.53 \\
\hline & & High & 0.69 & 7.43 & 2.19 & 0.95 \\
\hline & & Low & 19765 & 32068 & 26346 & 2137.9 \\
\hline & & High & 69918 & 116030 & 99783 & 9372.3 \\
\hline \multirow{4}{*}{$\stackrel{\infty}{E}$} & \multirow{4}{*}{$\begin{array}{l}\text { Slope } \\
\left(\mathrm{cm} \mathrm{km}^{-1}\right) \\
\text { Discharge } \\
\left(\mathrm{m}^{3} \mathrm{~s}^{-1}\right)\end{array}$} & Low & -0.12 & 4.99 & 0.5 & 1.02 \\
\hline & & High & 0.17 & 3.01 & 0.52 & 0.35 \\
\hline & & Low & -2649 & 5314 & 958 & 1276.4 \\
\hline & & High & 6665 & 19276 & 13466 & 2958.9 \\
\hline
\end{tabular}

$82 \mathrm{~h}$ to complete on a dual-processor compute server. The Manning's friction coefficient, $n$, used was 0.032 for the Solimões and 0.034 for the Purus, obtained from model calibration by Trigg et al. (2009). The overall RMSE of the model ranged between 0.1 and $0.9 \mathrm{~m}$ (please see Trigg et al., 2009 , for details). Model validation consisted of a comparison of model water levels with an independent set of satellite altimetry data, with RMSE found to be 1.26 and $1.42 \mathrm{~m}$ for the Solimões and Purus rivers, respectively (Trigg et al., 2009).

One-dimensional channel profiles outputs from the LISFLOOD-FP model are shown in Fig. 4 for low water (15 September 1995) and high water (21 June 1996), including the water-surface elevation, water-surface slope and channel discharge, and are summarised in Table 1. There was substantial along-channel variation in water-surface slope and channel discharge for the both the Solimões and the Purus at low and high water. This along-channel variability may make the accurate estimation of discharge using reach-averaged estimates of slope a considerably greater challenge.

Figure 5 indicates water elevation at the upstream and downstream ends of the Solimões and Purus reaches and average water-surface slopes throughout the 22-month simulation period. Generally, water-surface slope is lowest during the falling limb of the hydrograph and highest during the rising limb. Average water-surface slope for the Solimões rose quickly to its maximum level of $2.9 \mathrm{~cm} \mathrm{~km}^{-1}$ during the low water period (September to November, 1995), immediately after the river level at the upstream end of the channel started to rise. The maximum water-surface slope in the Purus of $1.29 \mathrm{~cm} \mathrm{~km}^{-1}$ occurred during the low water period (October, 1995), when backwater effects from the main Solimões channel were less important.

As detailed in Sect. 3.2, truth images of water-surface elevation, $h_{\text {[TRUE] }}$, were generated from LISFLOOD-FP according to the SWOT spatio-temporal sampling scheme and 2-D errors were then added to these according to the 2D SWOT science requirements height error spectrum, providing SWOT images of water-surface height observations, $h_{\text {[SWOTOBS] }}$. Over the 22-month simulation period, there were a total of 29 orbit cycles (of 22 days each and including six overpasses of the domain; see Fig. 3a) providing, in total, 174 images of $h_{\text {[SWOTOBS] }}$. An example set of six overpasses from a SWOT orbit cycle at high water (cycle 18) is shown in Fig. 6, illustrating the extent of the channel which may be observed. Note that here we are focused on the main channels and have not attempted to map water elevations in the floodplain forest. A detailed inset image of the Purus/ Solimões confluence for cycle 18, overpass 6 is shown in Fig. 7, illustrating the image of $h_{\text {[SWOTOBS] }}$ alongside the corresponding image of $h_{\text {[TRUE] }}$ and 2-D SWOT height errors.

Values of SWOT water-surface height observations were extracted from images of $h_{\text {[SWOTOBS] }}$ along the channel centerline and, in addition, averages of channel cross sections taken perpendicular to the channel centerline were calculated $\left(h_{[\text {SWOTXS }]}\right)$, plotted against distance downstream for high water (cycle 18) in Fig. 8. In these profiles, the tighter clustering of the cross-sectional averages to the true channel water elevation profile indicates that by taking a cross-sectional average, errors in water-surface height observations were reduced (assuming no bias in the estimation of water-surface elevation).

\subsection{Water-surface slopes}

Figure 9 illustrates along-channel water-surface slope as calculated using $h_{\text {[SWOTXS] }}$ for high water (cycle 18 , overpass 6), using reach lengths between 5 and $20 \mathrm{~km}$. As the length of averaging increased, errors in $S_{\text {[SWOTXS] }}$ reduced substantially when compared to $S_{\text {[TRUE] }}$. Overall error in the estimation of water-surface slope decreased quickly with increasing reach lengths (Fig. 10): for the Solimões, without averaging across channel $\left(S_{[\text {[SWOTOBS }]}\right)$ and with a short reach lengths of $0.5 \mathrm{~km}$, errors in slope were high at $86.4 \mathrm{~cm} \mathrm{~km}^{-1}$. These errors dropped quickly as more data were included in the estimation of slope, reducing to $0.33 \mathrm{~cm} \mathrm{~km}^{-1}$ at $20 \mathrm{~km}$. Averaging across channel in addition to along-reach lengths $\left(S_{\text {[SWOTXS] }}\right)$ led to a further drop in errors, with $0.09 \mathrm{~cm} \mathrm{~km}^{-1}$ error at $20 \mathrm{~km}$ reach lengths. Slope errors were similar for the Purus without cross-sectional averaging $\left(91.0 \mathrm{~cm} \mathrm{~km}^{-1}\right.$ at $0.5 \mathrm{~km}$; 0.31 at $20 \mathrm{~km}$ ), and were moderately higher than the Solimões with cross-sectional averaging $\left(0.13 \mathrm{~cm} \mathrm{~km}^{-1}\right.$ at $\left.20 \mathrm{~km}\right)$ due to the narrower channel width (Table 2). The science requirement for the SWOT sensor is that river slopes are measured with errors less than $1 \mathrm{~cm} \mathrm{~km}^{-1}$ when averaged for a $10 \mathrm{~km}$ reach length (Rodríguez, 2014). As expected from the methods used, for both the Solimões and Purus, without cross-sectional averaging $\left(S_{\text {[SWOTOBS }]}\right)$, reach lengths of $\sim 10 \mathrm{~km}$ were required to achieve this level of accuracy; with cross-sectional averaging $\left(S_{[\text {SWOTXS }]}\right)$, accuracies better than $1 \mathrm{~cm} \mathrm{~km}^{-1}$ were achieved using shorter reach lengths of $\sim 4$ and $\sim 5 \mathrm{~km}$ for the Solimões and Purus, respectively. For $10 \mathrm{~km}$ reach lengths, incorporating cross-sectional averaging, water-slope errors of 0.26 and $0.37 \mathrm{~cm}$ per $\mathrm{km}$, respectively, were achieved. 

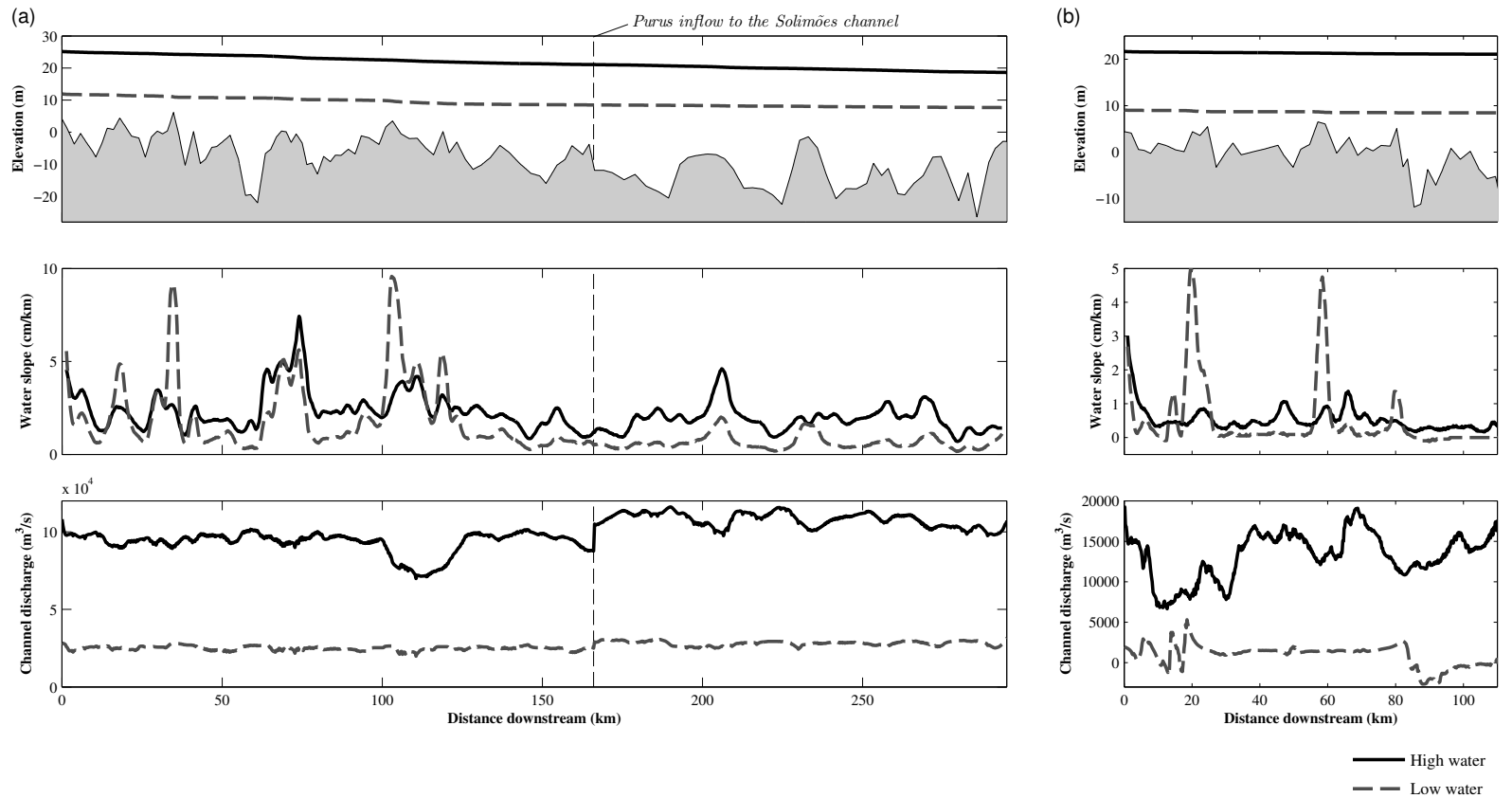

Figure 4. LISFLOOD-FP model output: 1-D channel profiles at high and low water for (a) the Solimões and (b) Purus rivers. Top: watersurface elevations along the channel (channel bed topography is shown in grey shaded area); middle: water-surface slope; bottom: channel discharge. The vertical line in the plots in (a) indicates the location of the Purus inflow to the Solimões.

(a)
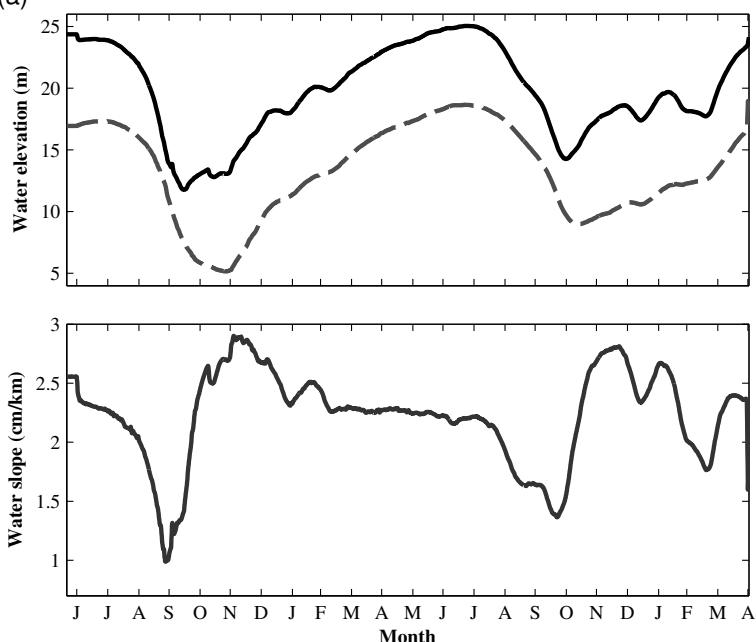

(b)
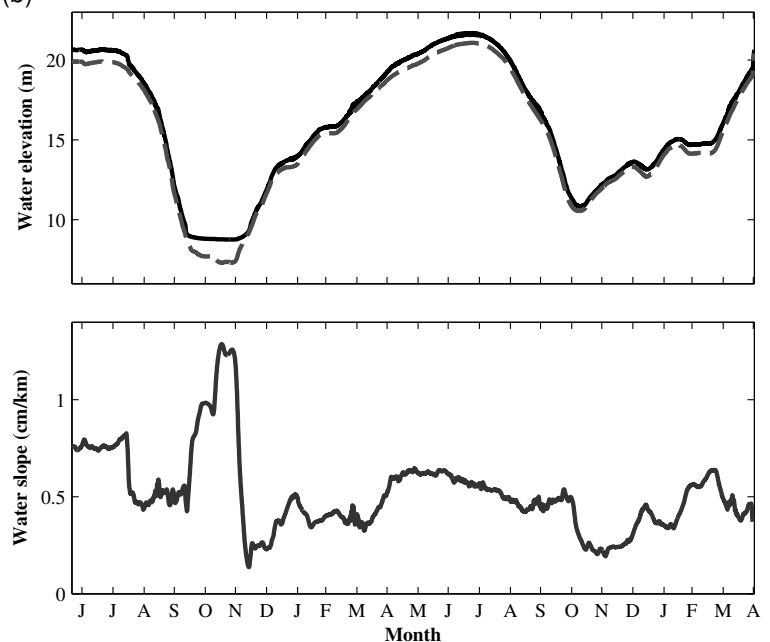

Figure 5. LISFLOOD-FP model output: 1-D channel profiles through time for (a) the Solimões and (b) the Purus rivers. Top plots: water elevations at the upstream (solid line) and downstream (dashed line) end of the study reach; bottom plots: average water-surface slope through time.

\subsection{Channel discharge}

In Fig. 11, along-channel discharge estimates for high water (cycle 18, overpass 6) are shown for $Q_{\text {[SwOTXS] us- }}$ ing reach lengths between 5 and $20 \mathrm{~km}$. As with errors in slope, as reach lengths increased, the errors in estimated discharge decreased. The LISFLOOD-FP modelled discharge ( $Q_{\text {[MODEL }]}$ is also shown for reference. Note that $Q_{\text {[TRUE] }}$ is different to $Q_{[\mathrm{MODEL}]}$ since it does not take into account the full diffusive wave approximation of the Saint Venant equations (Sect. 3.1) and is a reach-length average rather than an instantaneous discharge for a particular location.

Using reach lengths of $20 \mathrm{~km}$, full discharge hydrographs were constructed for $Q_{\text {[SWOTXS] }}$ for several locations along the Solimões and Purus channels, and are compared to hydrographs for $Q_{\text {[TRUE] }}$ and $Q_{\text {[MODEL] }}$ in Fig. 12. $Q_{\text {[SWOTXS] }}$ 

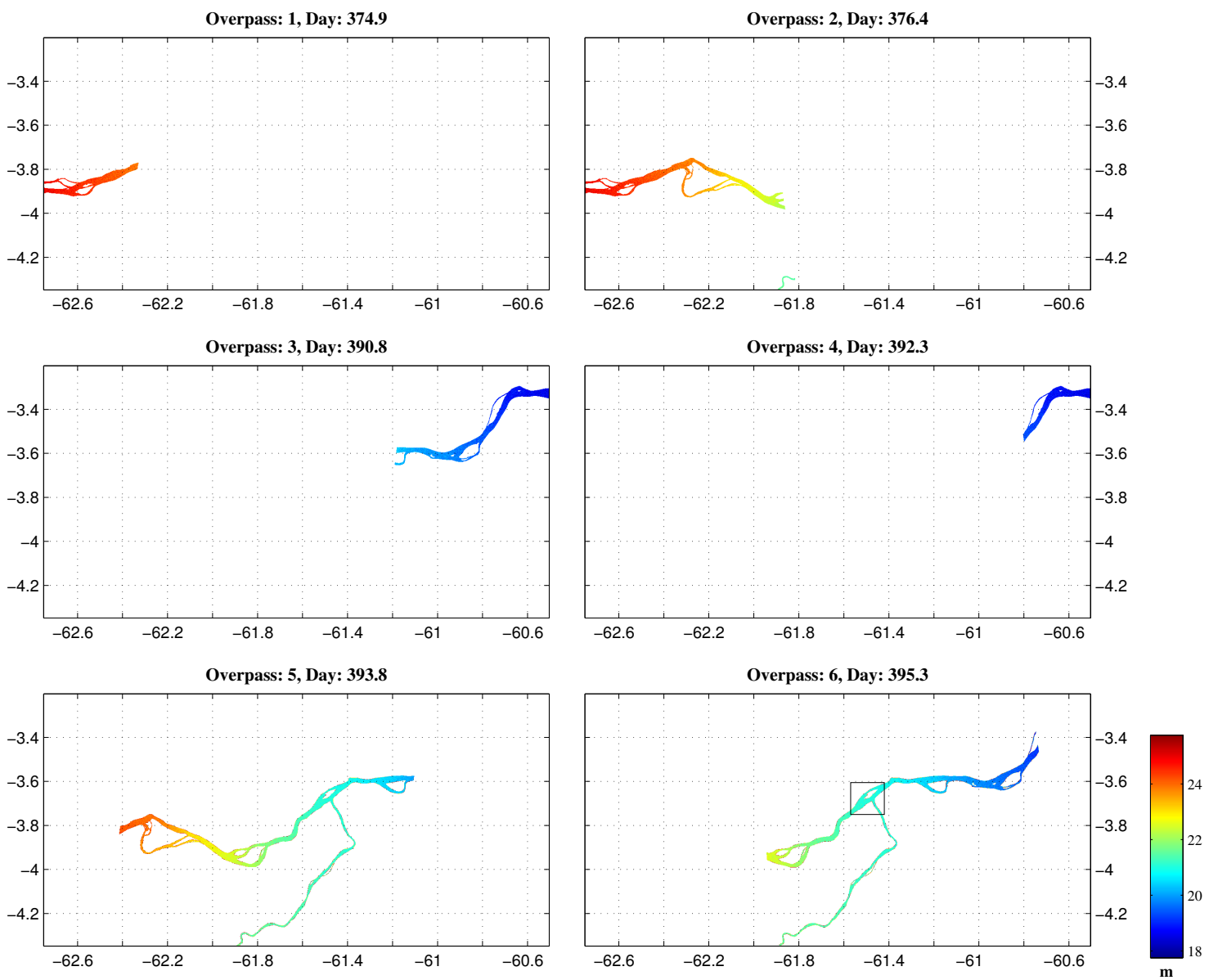

Figure 6. SWOT water elevation measurements derived from hydraulic model output (Figs. 4 and 5) and science requirements (Fig. 3) for cycle 18 (at high water), for each of the six overpasses during the 22-day cycle. The box shown in overpass 6 indicates the area shown in detail in Fig. 7.

(a)
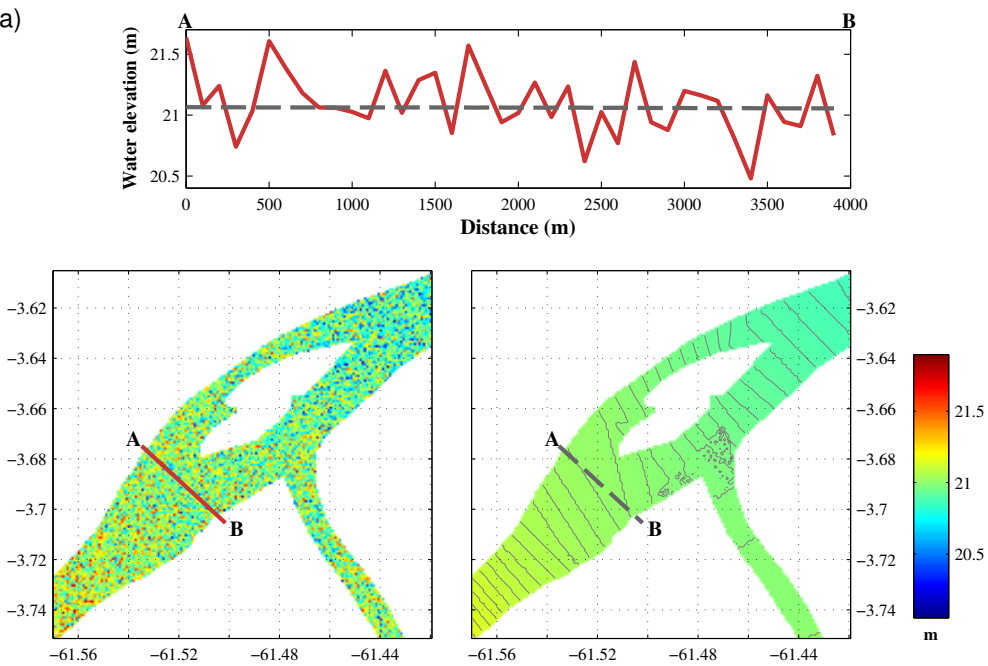

(b)

Figure 7. (a) Detail of 2-D SWOT water-surface elevation for cycle 18, overpass 6 (left) and corresponding "truth" water surface (right) with added $1 \mathrm{~cm}$ contours. Cross sections of water-surface elevation between points A and B are shown for illustrative purposes $\left(h_{[\mathrm{SWOTOBS}]}\right.$ is the solid red line; $h_{\text {[TRUE] }}$ is the dashed grey line). (b) 2-D SWOT errors generated by inverse Fourier transform of the spectrum (see Fig. 3b). 

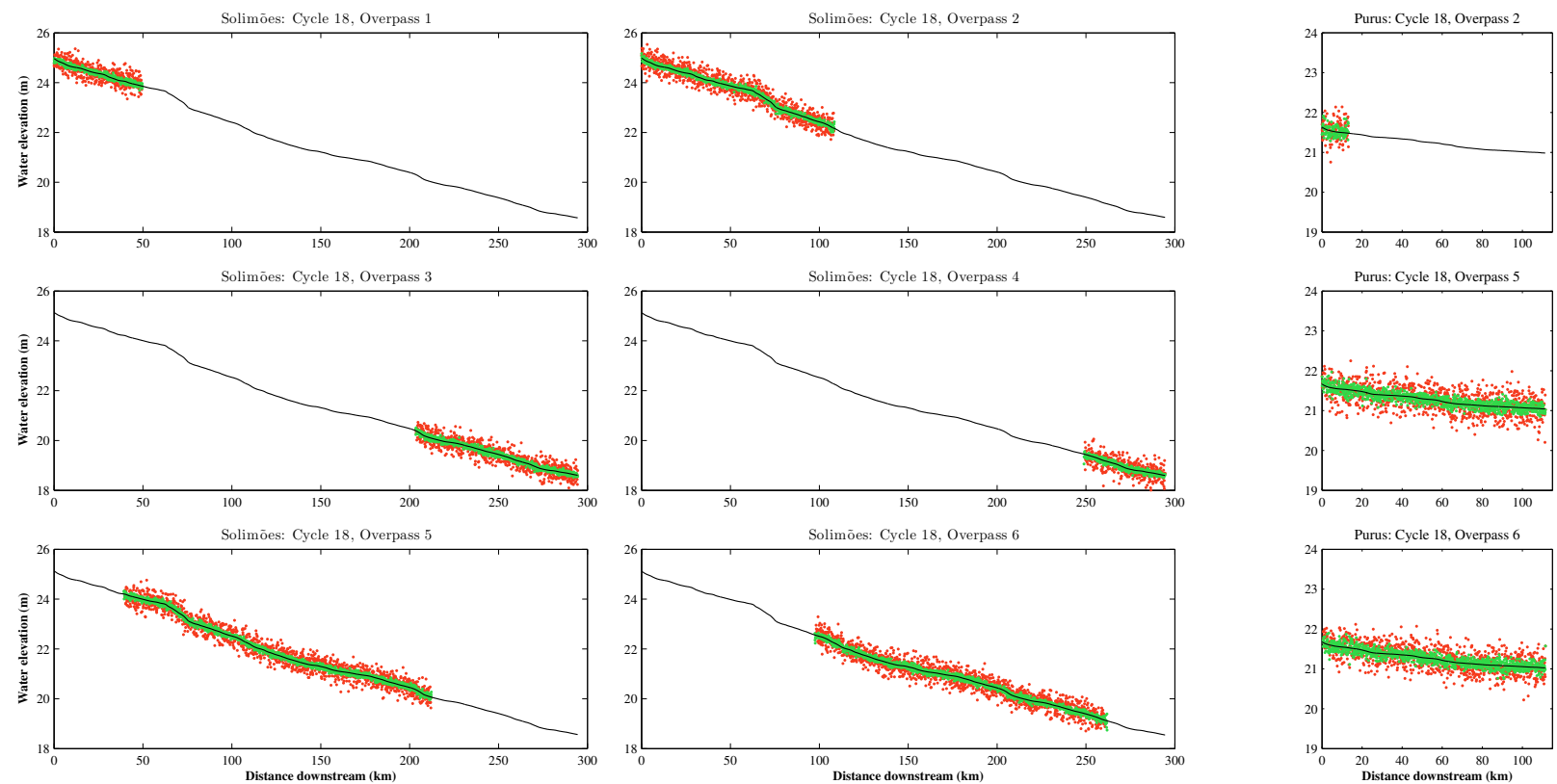

SWOT observation, $h_{\text {[SWOT OBS] }}$ SWOT x-section mean, $h_{[S W O T ~ X S]}$

Model channel profile

Figure 8. The 2-D heights (Fig. 6) were transferred to 1-D for both the Solimões and Purus by extracting values of $h_{[\mathrm{SWOTOBS}]}$ along the channel centerline; to reduce errors, averages of cross sections taken perpendicular to the channel centerline were also calculated $\left(h_{[\text {SWOTXS }]}\right)$.
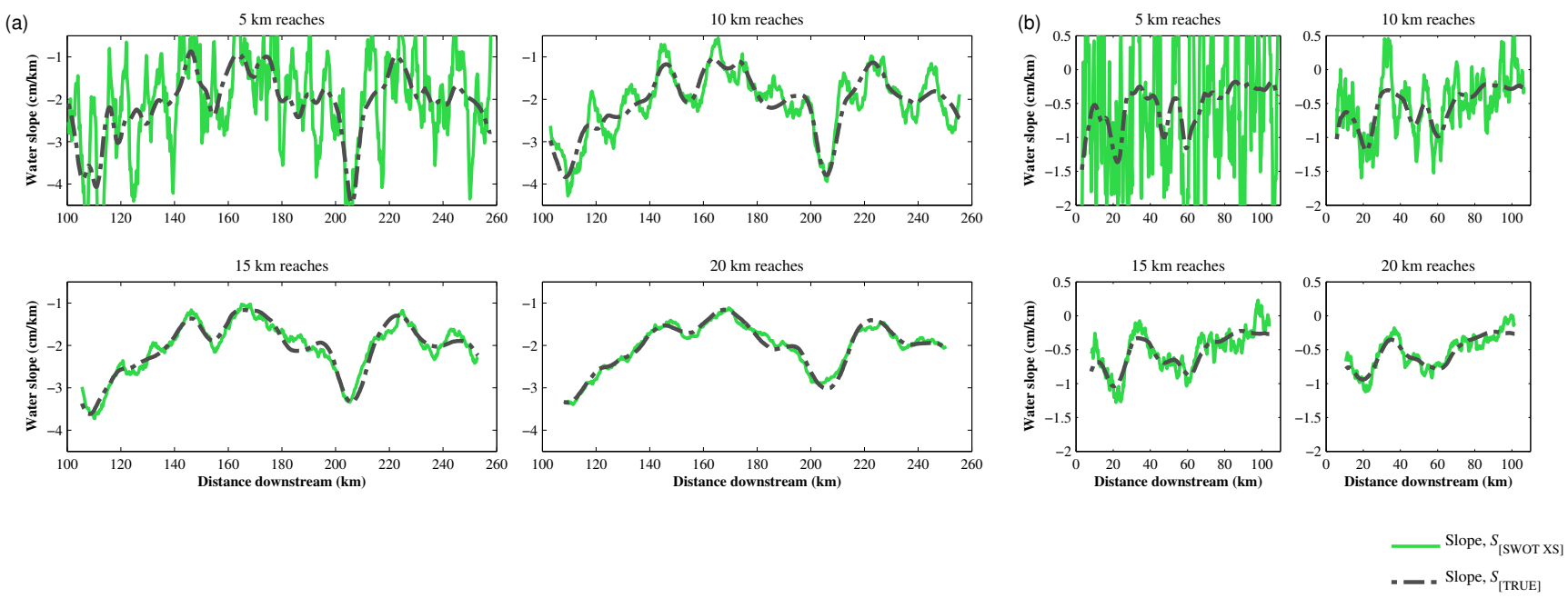

Figure 9. Slope errors: the effect of averaging along channel using reach lengths between 5 and $20 \mathrm{~km}$ for the (a) Solimões and (b) Purus rivers. Plots show cycle 18 (high water), overpass 6.

matched $Q_{\text {[TRUE] }}$ well throughout the 22-month hydrograph, including both rising and falling flood wave. As with slope errors, the error in estimated discharge dropped quickly as the length of reach-length averaging increased (Fig. 13). Without averaging water-surface elevations across channel $\left(Q_{\text {[SWOTOBS] }}\right)$, errors $(\mathrm{CV})$ were $48.5 \%$ of the mean Solimões discharge at $5 \mathrm{~km}$ reach lengths, reducing to $9.7 \%$ at $20 \mathrm{~km}$. Averaging across channel in addition to alongreach lengths $\left(Q_{[\text {SWOTXS }]}\right)$ led to a further drop in errors, with $22.2 \%$ error at a reach lengths of $5 \mathrm{~km}$, reducing to $2.6 \%$ at $20 \mathrm{~km}$. Discharge errors for the Purus without crosssectional averaging were $130.9 \%$ of the mean Purus discharge at $5 \mathrm{~km}$, reducing to $35.1 \%$ at $20 \mathrm{~km}$; conversely, with cross-sectional averaging errors were $76.0 \%$ at $5 \mathrm{~km}$, reduc- 
(a)

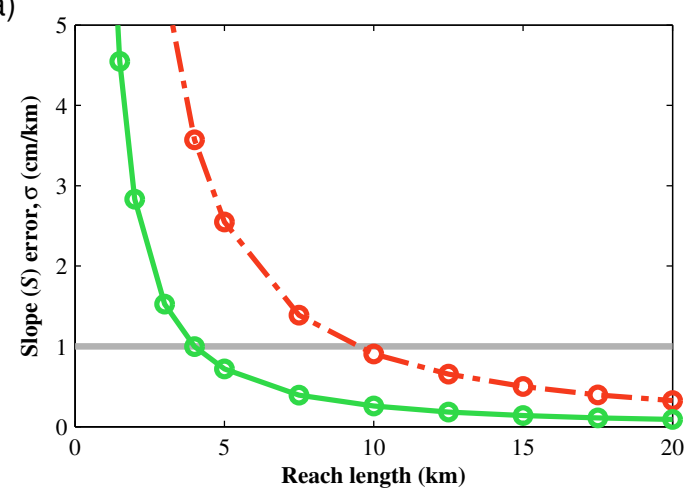

(b)

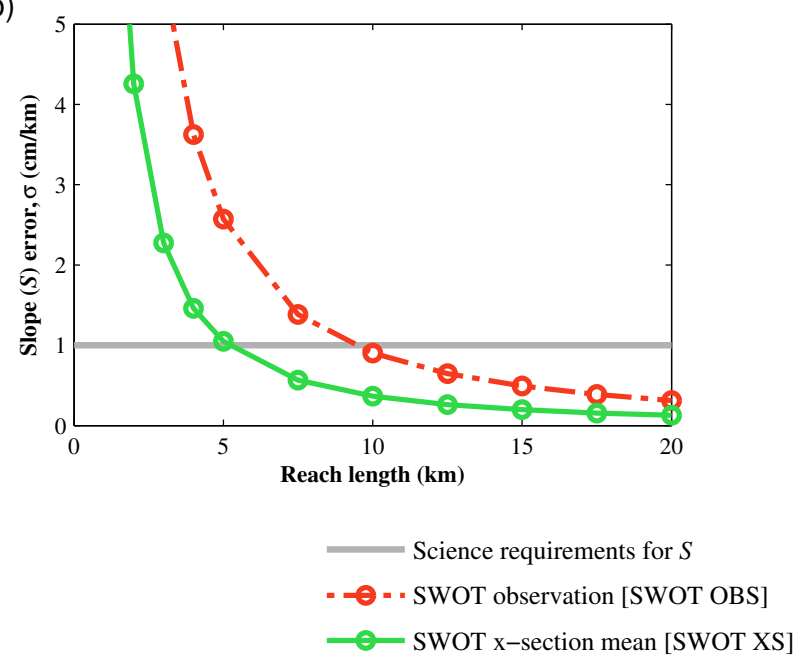

Figure 10. The effect of reach-length averaging on errors in the water-surface slope estimation for (a) the Solimões and (b) the Purus rivers.

ing to $19.1 \%$ at $20 \mathrm{~km}$. Discharge errors are summarised in Table 2.

Nash-Sutcliffe efficiency coefficient $(E)$ values for with increasing reach-length averaging are shown in Fig. 13c. On the Solimões, for $Q_{\text {[SwoтовS] }}, E$ was -1.92 at reach lengths of $5 \mathrm{~km}$, increasing to 0.89 at $20 \mathrm{~km}$; for $Q_{\text {[SWOTXS] }}, E$ was 0.46 at $5 \mathrm{~km}$, increasing to 0.99 at $20 \mathrm{~km}$. For the Purus, values of $E$ were lower: for $Q_{\text {[SwOTOBS] }}, E$ was -8.17 at reach lengths of $5 \mathrm{~km}$, increasing to 0.57 at $20 \mathrm{~km}$; for $Q_{\text {[SWOTXS] }}$, $E$ was -1.34 at $5 \mathrm{~km}$, increasing to 0.88 at $20 \mathrm{~km}$. Negative values of $E$ indicate that the prediction of discharge is no better than the mean value of the observations: consequently, using cross-sectional averaging, reach lengths of $\sim 4 \mathrm{~km}$ were required to achieve positive values of $E$ (indicating acceptable levels of accuracy) for the Solimões; for the Purus, $\sim 7.5 \mathrm{~km}$ reach lengths were required. High values of $E(>0.8)$ were achieved with reach lengths greater than $\sim 7.5 \mathrm{~km}$ for the Solimões and $\sim 17.5 \mathrm{~km}$ for the Purus, indicating high accuracy in the estimation of discharge.
Table 2. Summary of along-channel variability in modelled watersurface slope and channel discharge at low and high water.

\begin{tabular}{|c|c|c|c|c|c|}
\hline & \multicolumn{2}{|c|}{ Error } & \multicolumn{3}{|c|}{ Reach length $(\mathrm{km})$} \\
\hline \multirow{8}{*}{$\begin{array}{l}\stackrel{\mathscr{S}}{0} \\
\stackrel{0}{0} \\
\stackrel{0}{0}\end{array}$} & $S_{\text {[SWOTOBS }]}$ & $\sigma_{S}, \mathrm{~cm} \mathrm{~km}^{-1}$ & 2.55 & 0.91 & 0.33 \\
\hline & $S_{\text {[SWOTXS] }}$ & $\sigma_{S}, \mathrm{~cm} \mathrm{~km}^{-1}$ & 0.72 & 0.26 & 0.09 \\
\hline & & RMSE, $\mathrm{m}^{3} \mathrm{~s}^{-1}$ & 34180 & 18900 & 7190 \\
\hline & $Q_{[\text {SWOTOBS }]}$ & $\mathrm{CV}_{[\mathrm{RMSE}]}, \%$ & 48.5 & 26.1 & 9.7 \\
\hline & & $E$ & -1.92 & 0.23 & 0.89 \\
\hline & & RMSE, $\mathrm{m}^{3} \mathrm{~s}^{-1}$ & 15670 & 5950 & 1960 \\
\hline & $Q_{[\text {SWOTXS }]}$ & $\mathrm{CV}_{[\mathrm{RMSE}]}, \%$ & 22.2 & 8.3 & 2.6 \\
\hline & & $E$ & 0.46 & 0.93 & 0.99 \\
\hline \multirow{8}{*}{$\stackrel{\Xi}{\Xi}$} & $S_{\text {[SWOTOBS }]}$ & $\sigma_{S}, \mathrm{~cm} \mathrm{~km}^{-1}$ & 2.57 & 0.9 & 0.31 \\
\hline & $S_{\text {[SWOTXS] }}$ & $\sigma_{S}, \mathrm{~cm} \mathrm{~km}^{-1}$ & 1.05 & 0.37 & 0.13 \\
\hline & & RMSE, $\mathrm{m}^{3} \mathrm{~s}^{-1}$ & 9682 & 5211 & 2795 \\
\hline & $Q_{\text {[SWOTOBS }}$ & $\mathrm{CV}_{[\mathrm{RMSE}]}, \%$ & 130.9 & 67.9 & 35.1 \\
\hline & & $E$ & -8.17 & -0.92 & 0.57 \\
\hline & & RMSE, $\mathrm{m}^{3} \mathrm{~s}^{-1}$ & 5764 & 3189 & 1493 \\
\hline & $Q_{[\text {SWOTXS }]}$ & $\mathrm{CV}_{[\mathrm{RMSE}]}, \%$ & 76 & 40.9 & 19.1 \\
\hline & & $E$ & -1.34 & 0.44 & 0.88 \\
\hline
\end{tabular}

The above accuracy assessment of SWOT-derived discharge compares estimates obtained using SWOT observations of water elevation to those obtained using true watersurface elevations, based on the channel discharge approximation in Eq. (5), which does not take into account the full diffusive wave approximation of the Saint Venant equations shown in (1) and (2). To characterise error introduced by Eq. (5), $Q_{\text {[TRUE] }}$ and $Q_{\text {[SWOT] }}$ were also compared using $E$ to channel discharge obtained directly from LISFLOOD-FP, using $Q_{\text {[MODEL] }}$ in place of $Q_{\text {[TRUE] }}$ in Eq. (9) (Fig. 14). Thus, we were able to characterise errors in estimates of channel discharge introduced directly by errors in SWOT observations, as well as errors introduced by the calculation of $Q$ using reach-length averaging of the water surface in the calculation of water-surface slope. Errors in $Q_{\text {[TRUE] }}$ were low with a minimum error of $2418 \mathrm{~m}^{3} \mathrm{~s}^{-1}(3.5 \%, E=0.99)$ for the Solimões at a reach length of $0.75 \mathrm{~km}$, and $486 \mathrm{~m}^{3} \mathrm{~s}^{-1}$ $(6.8 \%, E=0.99)$ for the Purus at a reach length of $3 \mathrm{~km}$. However, as the reach length used increased, the errors in $Q_{\text {[TRUE] }}$ also increased. At reach lengths of $20 \mathrm{~km}$, errors for the Solimões were $5690 \mathrm{~m}^{3} \mathrm{~s}^{-1}(8.3 \%, E=0.87)$ and $1238 \mathrm{~m}^{3} \mathrm{~s}^{-1}(18.1 \%, E=0.89)$ for the Purus. This increase in error in conjunction with reach length is primarily a result of the reach-length averaging used for the calculation of water-surface slope in Eq. (4), as compared to the instantaneous discharge obtained at a single cross section from the LISFLOOD-FP model output. However, the figures should be used with caution since errors may also be related to the structure of the 1-D hydraulic model rather than resulting from differences with the true channel discharge at a location. Notwithstanding this, results illustrate that there may be an optimal reach length for the estimation of instanta- 
(a)
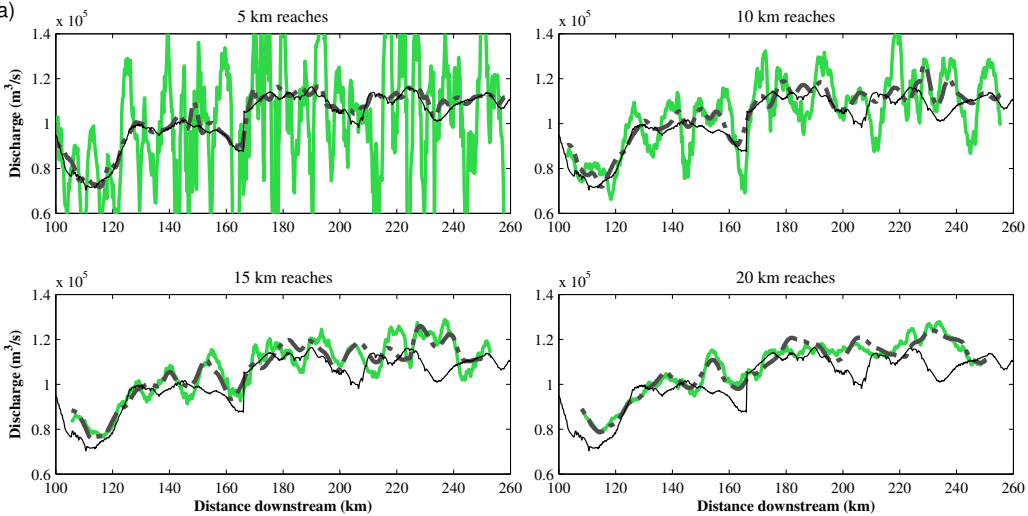
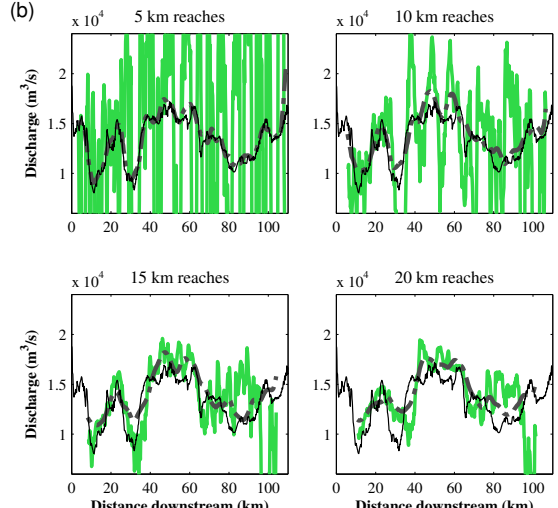

Discharge, $Q_{\text {[SWOT Xs }}$

- - . Discharge, $Q_{\text {[TRUE] }}$

Model discharge, $Q_{\text {[MODEL }}$

Figure 11. Discharge estimates accounting for slope errors but neglecting width, depth, and friction errors for reach lengths between 5 and $20 \mathrm{~km}$ for the (a) Solimões and (b) Purus rivers. Plots show cycle 18 (high water), overpass 6.
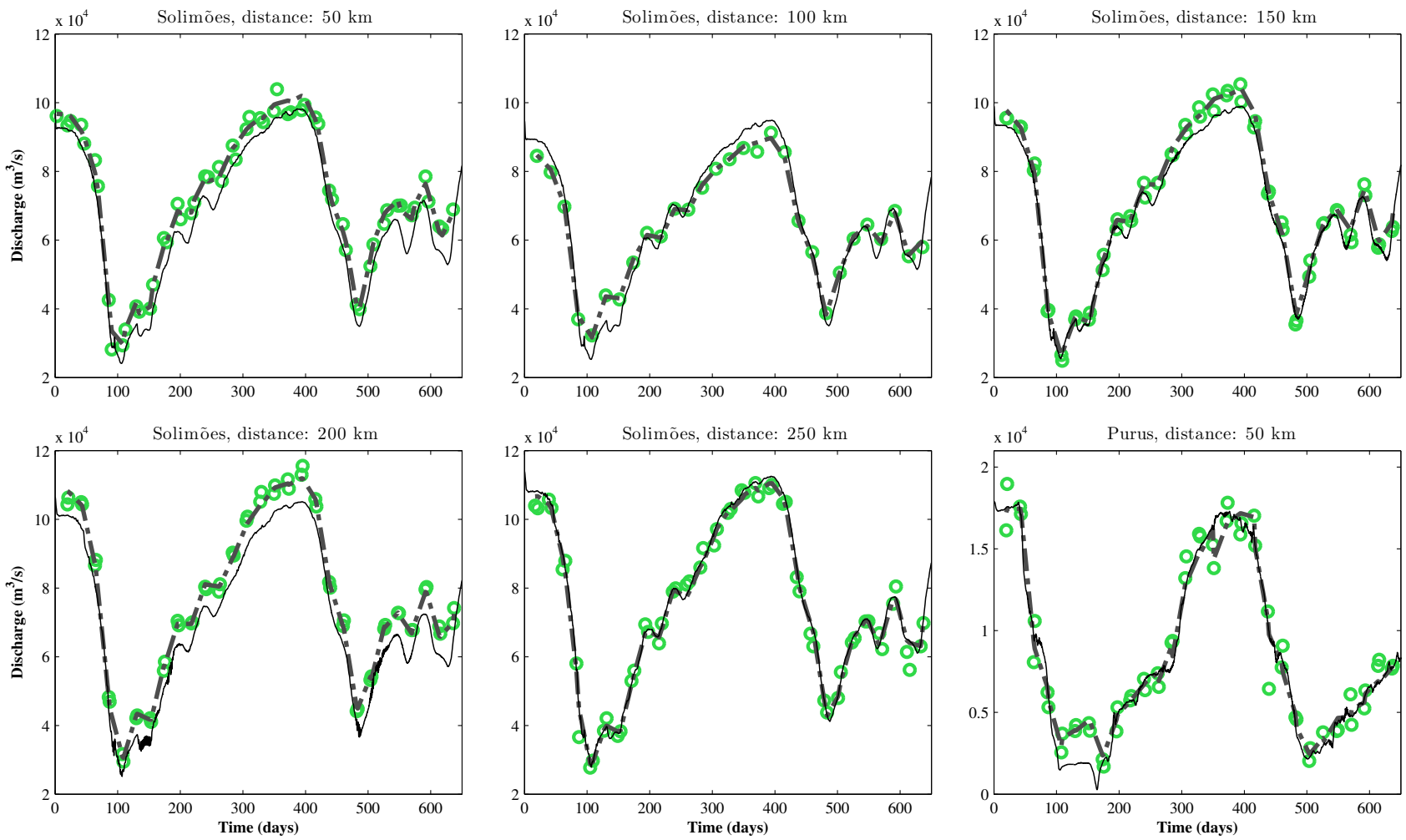

Discharge, $Q_{[\mathrm{SWOT} \text { XS }]}$
- _ - Discharge, $Q_{[\mathrm{TRUE}]}$
$\ldots$ Model discharge, $Q_{\text {[MODEL }]}$

Figure 12. Reconstruction of channel discharge hydrographs from cross-section-averaged SWOT observations $\left(Q_{[\mathrm{SWOTXS}]}\right)$ for the Solimões and Purus channels using $20 \mathrm{~km}$ reach lengths, compared to discharge obtained using water elevation "truth" images $\left(Q_{[\mathrm{TRUE}]}\right)$ and the original modelled channel discharge $\left(Q_{[\mathrm{MODEL}]}\right)$. 
(a)
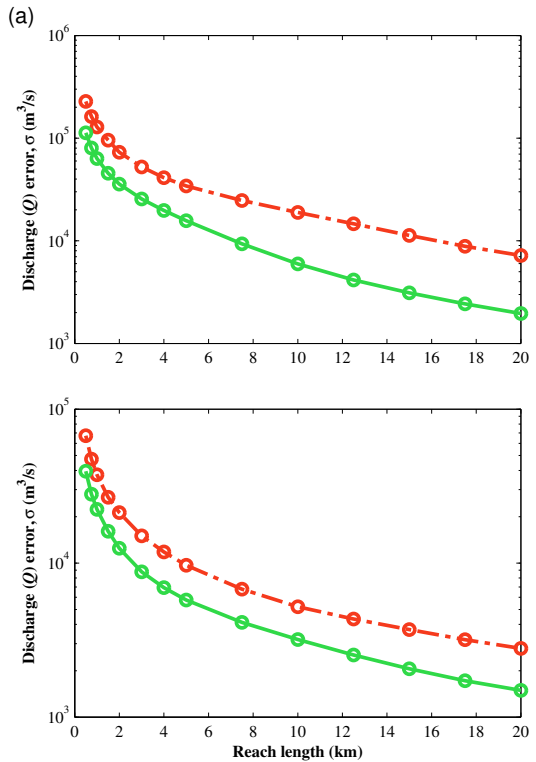
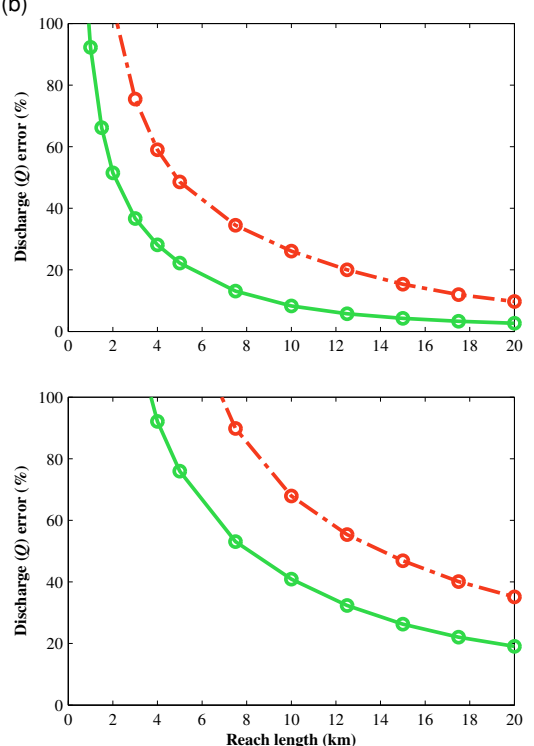

(c)
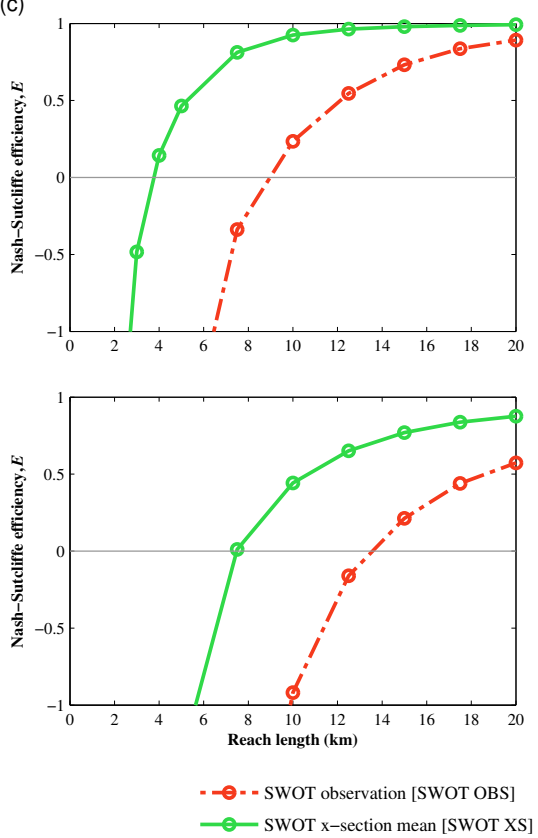

Figure 13. Errors in discharge $(Q)$ as related to reach-length averaging, calculated against slope and discharge obtained using water elevation "truth" images $\left(Q_{[\mathrm{TRUE}]}\right)$ : (a) absolute discharge error; (b) error expressed as a percentage of mean discharge; and (c) Nash-Sutcliffe efficiency coefficient. The horizontal line in (c) represents the level of "acceptable" error in modelled discharge estimates. Top row: Solimões; bottom row: Purus.

neous discharge, beyond which further averaging will lead to reductions in the accuracy of estimated discharge. For the Solimões, using cross-sectional averaging ( $Q_{\text {[SWOTXS] }}$ ), maximum accuracy occurred using reach lengths of $12.5 \mathrm{~km}$ $\left(6258 \mathrm{~m}^{3} \mathrm{~s}^{-1}\right.$ error, $\left.9.1 \%, E=0.89\right)$, beyond which accuracy decreased slightly. For comparison, at this reach length, errors in $Q_{\text {[TRUE] }}$ were $4.7 \%$, indicating that around $4.4 \%$ of the error was contributed from SWOT height errors with the remainder resulting from the method used to calculate discharge.

\subsection{Implications for SWOT}

These results indicate that discharge may be obtained accurately from SWOT measurements on large, lowland rivers, assuming sufficient knowledge of channel bathymetry and frictional properties. The error in discharge of $2.6 \%$ for the Solimões using cross-channel averaging and $20 \mathrm{~km}$ reach lengths compares favourably with the error of $\sim 6-8 \%$ obtained by LeFavour and Alsdorf (2005) for the same section of river using SRTM data and $733 \mathrm{~km}$ reach lengths. When comparing against instantaneous discharge obtained directly from model output, errors were moderately higher with accuracies of $9.1 \%$ obtained at reach lengths of $12.5 \mathrm{~km}$. This suggests that SWOT data will provide both an improvement in accuracy of discharge estimates and a substantial increase in the level of along-channel detail. Since SWOT will provide $2-\mathrm{D}$ measurements of surface water, we were able to use cross-channel averaging to substantially improve accuracy due to the improved representation of channel water-surface elevations and subsequent reductions in water-surface slope errors. For the Purus, accuracy in discharge estimates was lower, which is likely to have been in large part due to the narrower width of the river leading to a reduction in averaging of height errors and consequently higher slope errors, combined with the very low water-surface slopes on the river leading to a proportionately higher impact of slope errors when calculating discharge.

The results presented here may be extended to other large rivers which may be observable by SWOT via Eq. (6). In Fig. 15, the percentage error in calculated discharge, $Q$, resulting from errors in SWOT-derived water-surface slope are indicated for selected rivers, with approximate widths and water-surface slopes obtained from published sources. These errors were derived from Eq. (6) using $5 \mathrm{~km}$ reach lengths to estimate water-surface slope, incorporating the effects of cross-channel averaging of water-surface elevation and assuming that the full width of the channel is observable. As channel width increases, error in discharge decreases since greater averaging of water-surface elevation is possible (water-surface elevation errors will decrease by $1 / \sqrt{n}$, where $n$ is the number of pixels being averaged Rodríguez, 2014); as water-surface slope decreases, error in discharge increases since water-surface slope errors become proportionately more important according to Eq. (6). From this, we can infer that discharge estimates may be more accurate for 
(a)
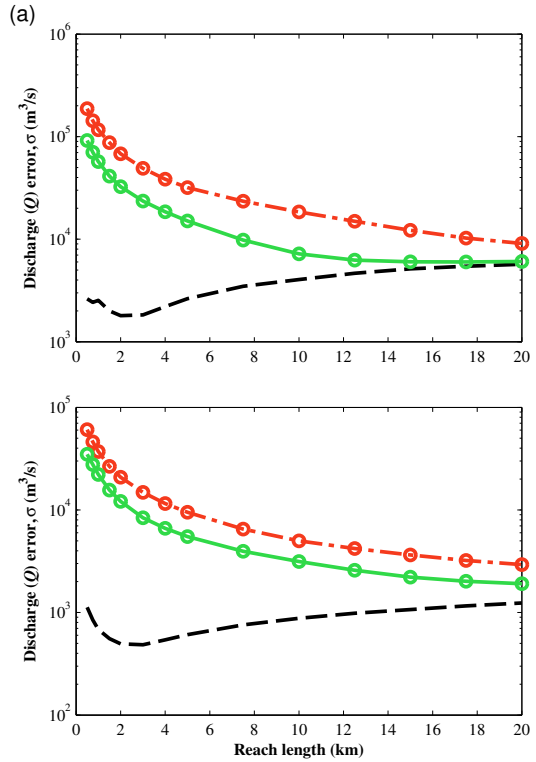

(b)
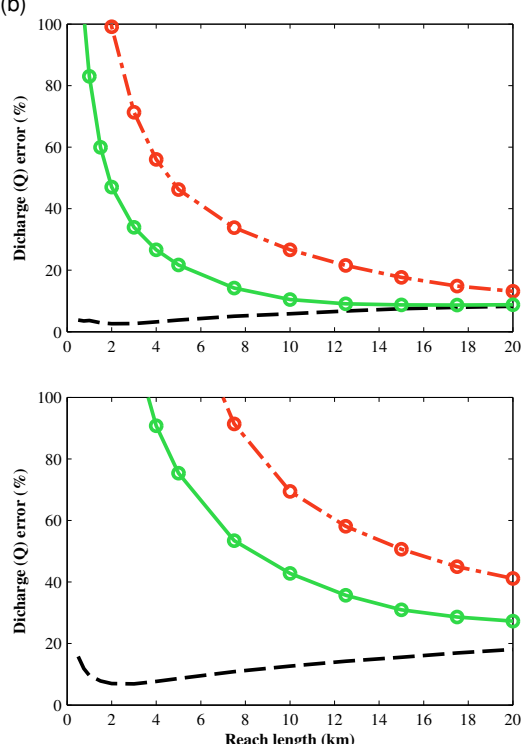

(c)
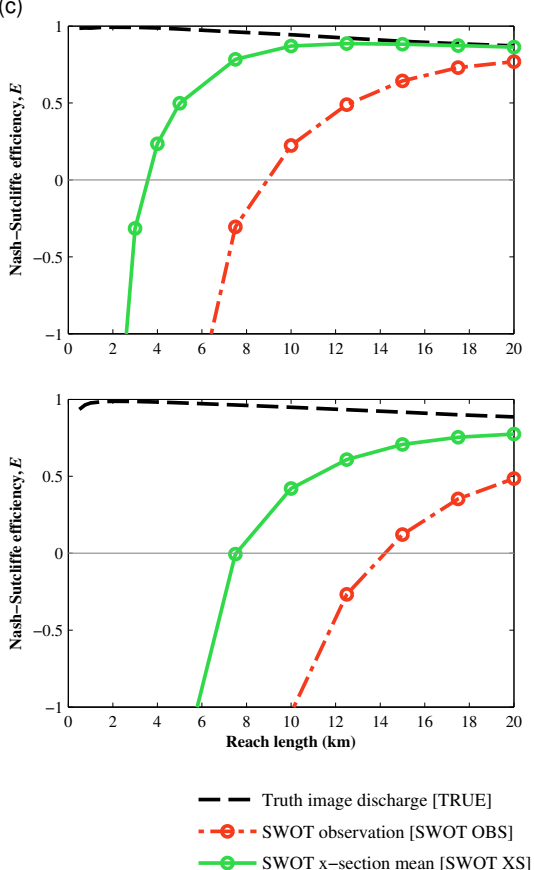

Figure 14. Errors in discharge $(Q)$ calculated against model discharge $\left(Q_{[\mathrm{MODEL}]}\right)$ : (a) absolute discharge error; (b) error expressed as a percentage of mean discharge; and (c) Nash-Sutcliffe efficiency coefficient. Top row: Solimões; bottom row: Purus.

rivers with (i) larger channel widths which permit a greater level of cross-sectional averaging and the use of shorter reach lengths and (ii) higher water-surface slopes, since the relative error in discharge decreases as slope increases. Conversely, discharge estimation accuracy is likely to be the lowest for narrow ( $<\sim 1 \mathrm{~km}$ width) rivers with low slopes, although further research is required to quantify errors for rivers at this scale. As indicated by the results presented in Fig. 13, longer reach lengths may lead to reduced error, at the expense of increasing along-channel approximation.

It is important to note that the errors presented here only represent the contribution to overall error in reach-averaged discharge which may be added by SWOT observations of water-surface elevation. Other errors are excluded but may be significant and further research is required to characterise their contribution (e.g. errors contributed by friction or bathymetry, or resulting from along-channel variability in discharge). Other than surface-water slope and elevation, parameters required in the estimation of discharge (i.e. channel width, roughness and bed elevation, or channel depth) are the subject of other recent studies. For example, Durand et al. (2008) used data assimilation of synthetic SWOT measurements in a hydraulic model to estimate river bathymetric slope and depth for the same river reach as presented in this paper, obtaining RMSE of $0.3 \mathrm{~cm} \mathrm{~km}^{-1}$ and $0.56 \mathrm{~m}$, respectively. Similarly, Yoon et al. (2012) estimated river bathymetry for the Ohio River, USA, obtaining an RMSE of $0.52 \mathrm{~m}$ and an effective reach-averaged river roughness within $1 \%$ of the true value. Finally, Durand et al. (2014) illustrated the use of a Bayesian algorithm to estimate river bathymetry and roughness based on observations of river $h$ and $S$ with high accuracy for the River Severn, UK, and the subsequent estimation of channel discharge. When compared to gauge estimates of discharge, Durand et al. (2014) obtained an accuracy of $10 \%$ in discharge estimation for inbank flows, assuming known lateral inflows, decreasing to $36 \%$ without this assumption. The work presented in this paper builds on these studies in that it is the first to directly assess the implications of errors in surface-water slope derived from SWOT observations of water elevation on the estimation of discharge, independent of other factors.

As with other studies, the error analysis presented here excluded layover and vegetation effects, as may be found in wetlands and floodplains, or along the edges of rivers. These effects are likely to be greatest for narrower rivers with bank vegetation. In addition, research presented here did not incorporate effects of the temporal sampling scheme on the accuracy of hydrograph estimation. For large rivers with discharge which changes relatively slowly, such as the Amazon and its sub-basins, errors introduced by SWOT temporal sampling are likely to be minimal. However, for smaller rivers with higher discharge variability, this sampling may be significant. Further research is required in this area, although it is likely that there will be an optimum level of width, slope, and discharge variability for discharge estimation. 


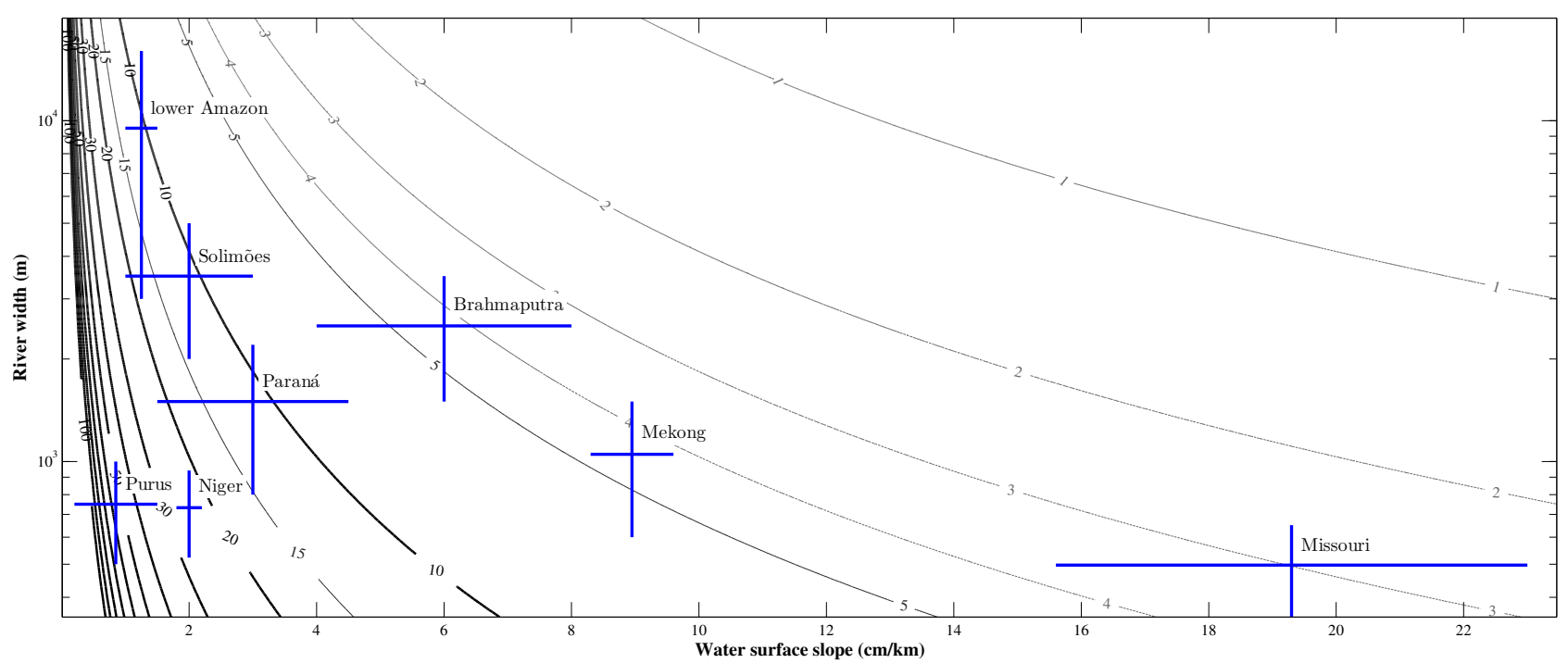

Figure 15. Examples of global rivers which may be observable by SWOT. Contours represent the percentage error in reach-averaged discharge $(Q)$, calculated according to Eq. (6), contributed by errors in water-surface slope derived from SWOT observations, when using $5 \mathrm{~km}$ reach lengths and cross-channel averaging. Errors may be reduced by using longer reach lengths; note that other sources of error are excluded but may be significant: without full assessment of each river, figures should be used with caution. Sources used to obtain values of river width and water-surface slopes were the Solimões and Purus rivers (Brazil) from this paper; lower Amazon River (Brazil) from Meade et al. (1985); Brahmaptura River (India) from Jung et al. (2010); Mekong River (Thailand/ Laos) from Birkinshaw et al. (2012); Missouri River (USA) from Bjerklie et al. (2005); Niger River (Mali) from Neal et al. (2012); and Paraná River (Argentina) from Depetris and Gaiero (1998).

\section{Conclusions}

In this paper, we used a virtual mission study of twodimensional water-surface elevations which may be obtained by SWOT for a reach of the central Amazon River in Brazil and investigated the implications of errors in such measurements on the estimation of water-surface slope and channel discharge. The following remarks can be made following our work:

1. Using 1-D polynomials with least-squares estimation fitted to water elevations obtained from channel centerlines, the SWOT design requirement of slope errors less than $1 \mathrm{~cm}$ per $\mathrm{km}$ when averaged for $10 \mathrm{~km}$ (Rodríguez, 2014) was achieved for both the Solimões and Purus Rivers.

2. Shorter reach lengths $(\sim 4$ and $\sim 5 \mathrm{~km}$ for the Solimões and Purus, respectively) were required to achieve the design level of accuracy when additionally averaging SWOT water-surface height estimates across-channel; for $10 \mathrm{~km}$ reach lengths, higher accuracies were achieved (water-slope errors of 0.26 and $0.37 \mathrm{~cm} \mathrm{~km}^{-1}$ for the Solimões and Purus, respectively). This indicates that the accuracy of water-surface slopes estimates will be higher for rivers with wider channels, particularly those several times wider than the $\sim 70-250 \mathrm{~m}$ nominal spatial resolution (Durand et al., 2010; Rodríguez, 2014).
3. SWOT data are promising for the estimation of Amazonian river discharge, with low errors in estimates $(9.1 \%$ for instantaneous estimates, or $2.6 \%$ for reach-averaged discharge estimates). Discharge hydrographs could be reconstructed accurately from SWOT imagery based on the specified temporal sampling scheme (Figure 3; Rodríguez, 2014) although, for rivers with a higher discharge variability, temporal sampling is likely to be a significant source of error for hydrograph estimation.

4. A high proportion of the errors found in the instantaneous estimates derived from the method used to calculate discharge from water-surface slopes, rather than from SWOT errors, suggesting that improvements to the estimation of discharge may be possible.

It should be noted that the errors added to water surfaces to simulate SWOT measurements of water elevation were spatially correlated at multiple scales (according to the SWOT design requirements error spectrum and incorporating longwavelength errors for each orbit), with added random noise on a per-pixel basis. While averaging along cross sections will effectively reduce the random noise component (assuming no bias), it was not immediately apparent how spatially correlated error would affect the estimation of discharge. Results here indicate that, at this scale, these errors do not greatly impact discharge accuracy - although similar assessments of other rivers is needed. 
Overall, these findings indicate that forthcoming SWOT imagery shows considerable promise for the hydraulic characterisation of large rivers such as the Amazon, although further work is required for a range of additional rivers with a variety of characteristics, particularly those with a high spatial and temporal variability in surface-water slope and channel discharge.

A final note of caution: in this paper, we assumed knowledge of channel friction, width, and bed elevation in the calculation of discharge, since our aim was to characterise the impact of SWOT observations and their associated errors independently of these issues. We also excluded the potential effects of vegetation on errors in SWOT surface water heights. Further work is needed to assess the relative importance of each of these factors on the estimation of channel discharge.

Acknowledgements. This research was completed while M. D. Wilson was a visiting researcher at the School of Earth Sciences, Ohio State University. M. Durand is supported by a NASA SWOT Science Definition Team Grant (no. NNX13AD96G). The authors would like to thank R. Romanowicz and one anonymous referee for their careful reviews and valuable recommendations which have improved the quality of this manuscript.

Edited by: R. Moussa

\section{References}

Alsdorf, D., Lettenmaier, D., and Vörösmarty, C.: The Need for Global, Satellite-based Observations of Terrestrial Surface Waters, Eos, Transactions American Geophysical Union, 84, 269275, doi:10.1029/2003EO290001, 2003.

Alsdorf, D., Bates, P., Melack, J., Wilson, M., and Dunne, T.: Spatial and temporal complexity of the Amazon flood measured from space, Geophys. Res. Lett., 34, L08402, doi:10.1029/2007GL029447, 2007a.

Alsdorf, D., Rodríguez, E., and Lettenmaier, D.: Measuring surface water from space, Rev. Geophys., 45, RG2002, doi:10.1029/2006RG000197, 2007b.

Bates, P. and De Roo, A.: A simple raster-based model for flood inundation simulation, J. Hydrol., 236, 54-77, doi:10.1016/S00221694(00)00278-X, 2000.

Berry, P. A. M., Garlick, J. D., Freeman, J., and Mathers, E.: Global inland water monitoring from multi-mission altimetry, Geophys. Res. Lett., 32, L16401, doi:10.1029/2005GL022814, 2005.

Birkett, C.: Contribution of the TOPEX NASA Radar Altimeter to the global monitoring of large rivers and wetlands, Water Resour. Res., 34, 1223-1239, doi:10.1029/98WR00124, 1998.

Birkett, C., Mertes, L., Dunne, T., Costa, M., and Jasinski, M.: Surface water dynamics in the Amazon Basin: Application of satellite radar altimetry, J. Geophys. Res., 107, 8059, doi:10.1029/2001JD000609, 2002.

Birkinshaw, S. J., Moore, P., Kilsby, C., O’Donnell, G. M., Hardy, A., and Berry, P. A. M.: Daily discharge estimation at ungauged river sites using remote sensing, Hydrol. Process., 28, 10431054, doi:10.1002/hyp.9647, 2012.

Bjerklie, D., Lawrencedingman, S., Vorosmarty, C., Bolster, C., and Congalton, R.: Evaluating the potential for measuring river discharge from space, J. Hydrol., 278, 17-38, doi:10.1016/S00221694(03)00129-X, 2003.

Bjerklie, D. M., Moller, D., Smith, L. C., and Dingman, S. L.: Estimating discharge in rivers using remotely sensed hydraulic information, J. Hydrol., 309, 191-209, doi:10.1016/j.jhydrol.2004.11.022, 2005.

Depetris, P. J. and Gaiero, D. M.: Water-surface slope, total suspended sediment and particulate organic carbon variability in the Parana River during extreme flooding, Naturwissenschaften, 85, 26-28, doi:10.1007/s001140050445, 1998.

Durand, M., Andreadis, K. M., Alsdorf, D. E., Lettenmaier, D. P., Moller, D., and Wilson, M.: Estimation of bathymetric depth and slope from data assimilation of swath altimetry into a hydrodynamic model, Geophys. Res. Lett., 35, L20401, doi:10.1029/2008GL034150, 2008.

Durand, M., Fu, L.-L., Lettenmaier, D., Alsdorf, D., Rodríguez, E., and Esteban-Fernandez, D.: The Surface Water and Ocean Topography Mission: Observing Terrestrial Surface Water and Oceanic Submesoscale Eddies, P. IEEE, 98, 766-779, doi:10.1109/JPROC.2010.2043031, 2010.

Durand, M., Neal, J., Rodríguez, E., Andreadis, K. M., Smith, L. C., and Yoon, Y.: Estimating reach-averaged discharge for the River Severn from measurements of river water surface elevation and slope, J. Hydrol., 511, 92-104, doi:10.1016/j.jhydrol.2013.12.050, 2014.

Fekete, B. M. and Vörösmarty, C.: The current status of global river discharge monitoring and potential new technologies complementing traditional discharge measurements, in: Predictions in Ungauged Basins: PUB Kick-off (Proceedings of the PUB Kickoff meeting held in Brasilia, 20-22 November 2002). IAHS Publ. 309, November 2002, 129-136, IAHS, Wallingford, UK, 2007.

Hossain, F., Katiyar, N., Hong, Y., and Wolf, A.: The emerging role of satellite rainfall data in improving the hydro-political situation of flood monitoring in the under-developed regions of the world, Nat. Hazards, 43, 199-210, doi:10.1007/s11069-0069094-x, 2007.

Jung, H. C., Hamski, J., Durand, M., Alsdorf, D., Hossain, F., Lee, H., Hossain, A. K. M. A., Hasan, K., Khan, A. S., and Hoque, A. Z.: Characterization of complex fluvial systems using remote sensing of spatial and temporal water level variations in the Amazon, Congo, and Brahmaputra Rivers, Earth Surf. Process. Land., 35, 294-304, doi:10.1002/esp.1914, 2010.

Kiel, B., Alsdorf, D., and Lefavour, G.: Capability of SRTM C- and $\mathrm{X}$-band DEM Data to Measure Water Elevations in Ohio and the Amazon, Photogramm. Eng. Rem. S., 72, 1-8, 2006.

Lambin, J., Morrow, R., Fu, L.-L., Willis, J. K., Bonekamp, H., Lillibridge, J., Perbos, J., Zaouche, G., Vaze, P., Bannoura, W., Parisot, F., Thouvenot, E., Coutin-Faye, S., Lindstrom, E., and Mignogno, M.: The OSTM/Jason-2 Mission, Mar. Geod., 33, 425, doi:10.1080/01490419.2010.491030, 2010.

LeFavour, G. and Alsdorf, D.: Water slope and discharge in the Amazon River estimated using the shuttle radar topography mission digital elevation model, Geophys. Res. Lett., 32, L17404, doi:10.1029/2005GL023836, 2005. 
Legates, D. R. and McCabe, G. J.: Evaluating the use of "goodness-of-fit" Measures in hydrologic and hydroclimatic model validation, Water Resour. Res., 35, 233-241, doi:10.1029/1998WR900018, 1999.

Meade, R. H., Dunne, T., Richey, J. E., DE M Santos, U., and Salati, E.: Storage and remobilization of suspended sediment in the lower Amazon river of Brazil, Science, 228, 488-90, doi:10.1126/science.228.4698.488, 1985 .

Meade, R. H., Rayol, J. M., Conceicão, S. C., and Natividade, J. R. G.: Backwater effects in the Amazon River basin of Brazil, Environ. Geol. Water S., 18, 105-114, doi:10.1007/BF01704664, 1991.

Moriasi, D. N., Arnold, J. G., Van Liew, M. W., Bingner, R. L., Harmel, R. D., and Veith, T. L.: Model Evaluation Guidelines for Systematic Quantification of Accuracy in Watershed Simulations, T. ASABE, 50, 885-900, doi:10.13031/2013.23153, 2007.

Nash, J. and Sutcliffe, J.: River flow forecasting through conceptual models part I - A discussion of principles, J. Hydrol., 10, 282 290, doi:10.1016/0022-1694(70)90255-6, 1970.

Neal, J., Schumann, G., and Bates, P.: A subgrid channel model for simulating river hydraulics and floodplain inundation over large and data sparse areas, Water Resour. Res., 48, W11506, doi:10.1029/2012WR012514, 2012.

NRC: Earth science and applications from space: National imperatives for the next decade and beyond, National Acadamies Press, Washington, DC, available at: http://www.nap.edu/catalog.php? record_id=11820 (last access: 1 August 2014), 2007.

NSTC: Science and technology to support fresh water availability in the United States, Tech. Rep. November, National Science and Technology Council, Committee on Environment and Natural Resources, subcommittee on Water Availability and Quality, Washington, DC, available at: http://water.usgs.gov/owq/swaq. pdf, last access: 1 August 2004.

Papa, F., Bala, S. K., Pandey, R. K., Durand, F., Gopalakrishna, V. V., Rahman, A., and Rossow, W. B.: Ganga-Brahmaputra river discharge from Jason-2 radar altimetry: An update to the longterm satellite-derived estimates of continental freshwater forcing flux into the Bay of Bengal, J. Geophys. Res., 117, C11021, doi:10.1029/2012JC008158, 2012

Richey, J. E., Nobre, C., and Deser, C.: Amazon river discharge and climate variability: 1903 to 1985, Science (New York, N.Y.), 246, 101-103, doi:10.1126/science.246.4926.101, 1989.
Rodríguez, E.: Surface Water and Ocean Topography Mission (SWOT): Science Requirements Document, Tech. rep., NASA Jet Propulsion Laboritory, available at: http://swot.jpl.nasa.gov/ files/swot/SWOT_Science_Requirements_Document.pdf, last access: 1 August 2014.

Seyler, F., Calmant, S., Silva, J. S. D., Moreira, D. M., Mercier, F., and Shum, C.: From TOPEX/Poseidon to Jason-2/OSTM in the Amazon basin, Adv. Space Res., 51, 1542-1550, doi:10.1016/j.asr.2012.11.002, 2013.

Shiklomanov, A. I., Lammers, R., and Vörösmarty, C.: Widespread decline in hydrological monitoring threatens Pan-Arctic research, Eos, Transactions American Geophysical Union, 83, 13 17, doi:10.1029/2002EO000008, 2002.

Trigg, M., Wilson, M. D., Bates, P. D., Horritt, M. S., Alsdorf, D. E., Forsberg, B. R., and Vega, M. C.: Amazon flood wave hydraulics, J. Hydrol., 374, 92-105, doi:10.1016/j.jhydrol.2009.06.004, 2009.

USGS: A New Evaluation of the USGS Streamgaging Network: A Report to Congress, Tech. rep., United States Geological Survey, available at: http://water.usgs.gov/streamgaging/report.pdf (last access: 1 August 2014), 1998.

Vorosmarty, C., Askew, A., Grabs, W., Barry, R. G., Birkett, C., Doll, P., Goodison, B., Hall, A., Jenne, R., Kitaev, L., Landwehr J., Keeler, M., Leavesley, G., Schaake, J., Strzepek, K., Sundarvel, S. S., Takeuchi, K., and Webster, F.: Global water data: A newly endangered species, Eos, Transactions American Geophysical Union, 82, 54-54, doi:10.1029/01EO00031, 2001.

Wilson, M., Bates, P., Alsdorf, D., Forsberg, B., Horritt, M., Melack, J., Frappart, F., and Famiglietti, J.: Modeling large-scale inundation of Amazonian seasonally flooded wetlands, Geophys. Res. Lett., 34, L15404, doi:10.1029/2007GL030156, 2007.

Wolf, A. T., Natharius, J. A., Danielson, J. J., Ward, B. S., and Pender, J. K.: International River Basins of the World, Int. J. Water Resour. D., 15, 387-427, doi:10.1080/07900629948682, 1999.

Yoon, Y., Durand, M., Merry, C. J., Clark, E. a., Andreadis, K. M., and Alsdorf, D. E.: Estimating river bathymetry from data assimilation of synthetic SWOT measurements, J. Hydrol., 464-465, 363-375, doi:10.1016/j.jhydrol.2012.07.028, 2012. 